\title{
Secondary Bacterial Infections Associated with Influenza Pandemics
}

\author{
Denise E. Morris ${ }^{1 *}$, David W. Cleary ${ }^{1}$ and Stuart C. Clarke ${ }^{1,2,3 *}$ \\ 1 Infectious Disease Epidemiology Group, Academic Unit of Clinical and Experimental Sciences, Faculty of Medicine, Institute \\ for Life Sciences, University of Southampton, University Hospital Southampton Foundation NHS Trust, Southampton, \\ United Kingdom, ${ }^{2}$ Global Health Research Institute, University of Southampton, Southampton, United Kingdom, \\ ${ }^{3}$ NIHR Southampton Respiratory Biomedical Research Unit, Southampton, United Kingdom
}

OPEN ACCESS

Edited by:

Chew Chieng Yeo,

Universiti Sultan Zainal Abidin,

Malaysia

Reviewed by: Jeanette Teo,

National University Hospital,

Singapore

Siomar De Castro Soares,

Universidade Federal do Triângulo

Mineiro, Brazi

Chanwit Tribuddharat,

Siriraj Hospital, Thailand

*Correspondence:

Stuart C. Clarke

s.c.clarke@soton.ac.uk

Denise E. Morris

d.e.morris@soton.ac.uk

Specialty section:

This article was submitted to

Evolutionary and Genomic

Microbiology,

a section of the journal

Frontiers in Microbiology

Received: 04 April 2017

Accepted: 24 May 2017

Published: 23 June 2017

Citation:

Morris DE, Cleary DW and Clarke SC (2017) Secondary Bacterial Infections Associated with Influenza Pandemics. Front. Microbiol. 8:1041.

doi: 10.3389/fmicb.2017.01041
Lower and upper respiratory infections are the fourth highest cause of global mortality (Lozano et al., 2012). Epidemic and pandemic outbreaks of respiratory infection are a major medical concern, often causing considerable disease and a high death toll, typically over a relatively short period of time. Influenza is a major cause of epidemic and pandemic infection. Bacterial co/secondary infection further increases morbidity and mortality of influenza infection, with Streptococcus pneumoniae, Haemophilus influenzae, and Staphylococcus aureus reported as the most common causes. With increased antibiotic resistance and vaccine evasion it is important to monitor the epidemiology of pathogens in circulation to inform clinical treatment and development, particularly in the setting of an influenza epidemic/pandemic.

Keywords: influenza, Streptococcus pneumoniae, Haemophilus influenzae, Staphylococcus aureus, pandemic

\section{INTRODUCTION}

From the Plague of Athens to the present day, infectious disease has beset mankind throughout history. Medical and socio-economic advances have substantially reduced this burden, the eradication of smallpox in 1979 (World Health Organization, 2017) and the remarkable successes against polio and parasitic Guinea worm disease being three examples of an extensive list. Respiratory tract infections, however, continue to be a major cause of morbidity and mortality worldwide (Lozano et al., 2012; Morse et al., 2012; Zumla et al., 2014). When combined, lower and upper respiratory infections are the fourth highest cause of global mortality (Lozano et al., 2012). Epi- and pandemic outbreaks of respiratory infection are a major medical concern, often causing considerable disease and a high death toll, typically over a relatively short period of time. The unpredictable nature of these outbreaks, in terms of their etiology and the reservoirs from which they emerge, the constant emergence of new antigenic variants by mutation, combined with transmission within potentially immunologically naïve populations facilitates the characteristic high proficiency of spread (Morse et al., 2012).

It is well established that both animals and humans can act as reservoirs of infection within which pathogens may adapt and evolve. Examples include Coxiella burnetii which typically causes Q fever in cattle, sheep and goats but can also infect humans (Eldin et al., 2017), the plague causing Yersinia pestis, infamously transmitted to humans by rats via a flea vector (Yang et al., 2016b), human immunodeficiency virus (HIV) which originated in non-human primates before spreading into the human population (Rupp et al., 2016) and of course the most common example, influenza, which circulates within and between swine, avian and human hosts (amongst others). This cross-species flow can lead to adaptations that result in an increased pathogenicity to susceptible hosts, creating the potential for localized outbreaks or global spread (Murphy, 1998; 
Karesh et al., 2012; Morse et al., 2012). Important evolutionary modifications can occur during the timespan of an individual infection, permitting new and evolved strains of pathogens to emerge at an increased rate (Karesh et al., 2012). The evolution of pathogens (particularly zoonotic pathogens which account for $60 \%$ of human infectious diseases), and development of pandemics and epidemics, can be described in ecological principles whereby changing environmental pressures or opportunities drive a pathogen to exploit new niches or hosts to survive and thrive. This evolution is influenced by a range of anthropogenic factors, which include population expansion, changing land use and habitat destruction, selective pressures of increased antimicrobial usage, vaccination, global trade and travel (Daszak, 2012; Karesh et al., 2012; Morse et al., 2012).

Pandemics are generally viral in cause. This is thought to be due to their high mutation rate, which is particularly true for RNA viruses such as influenza where high nucleotide substitution and poor proof reading leads to the accumulation of errors in newly synthesized RNA strands. Influenza can also undergo re-assortment during mixed infection. These factors can result in divergence of surface antigens, such as haemagglutinin (HA) and neuraminidase (NA), producing strains not recognized by the human immune system and not covered by extant vaccines (Holland et al., 1982; Webster et al., 1992; Chen and Holmes, 2006; Hampson and Mackenzie, 2006; Jones et al., 2008; Taubenberger and Morens, 2008; Dormitzer et al., 2011; Morse et al., 2012). For instance, influenza A is now known to have 18 subtypes of $\mathrm{HA}$ and 11 subtypes of NA (Li et al., 2012; Tong et al., 2012; Wu et al., 2014). This high mutation rate and the emergence of new strains can also make vaccine development and policy difficult to plan and carry out. Due to viral antigenic shift, yearly influenza vaccines are required so the population is sufficiently protected by the vaccine, however, vaccine composition is determined $\sim 8$ months in advance of administration. This lag may allow new strains to emerge or for antigenic drift to result in a poor match between vaccine and the circulating strain of influenza. Furthermore as seen in the 2009 influenza pandemic, governments and public health departments face considerable difficulties in the production and distribution of vaccines when faced with sudden or unexpected outbreaks of newly emerged strains (Houser and Subbarao, 2015).

A common complication of respiratory viral disease can be secondary bacterial infection. Noting this association is important as it has clear implications for global health, principally because bacterial co/secondary infection is known lead to increased morbidity (Smith and McCullers, 2014). Co/secondary bacterial infection, as the name suggests, is a bacterial infection that occurs during or after an infection from another pathogen, commonly viruses. A number of viral infections (including infection from influenza virus, respiratory syncytial virus, parainfluenza virus and human metapneumovirus) can be complicated by co/secondary infection by a variety of bacteria including Streptococcus pneumoniae, Haemophilus influenzae, and Staphylococcus aureus. This association leads to an increased severity of disease and sequela such as pneumonia (Smith and McCullers, 2014). In this review we dwell on influenza pandemics since the late 1800 's, focussing on the associations and complications that arise from secondary bacterial infections.

\section{INFLUENZA}

Influenza viruses are important zoonotic pathogens as they are highly contagious and one of the most prevalent causes of respiratory infection. Worldwide annual epidemics reportedly cause up to five million cases of severe illness, which result in 250,000-500,000 deaths per year. The majority of deaths caused by influenza occur in young children and people over 65 (World Health Organization, 2016). Reports suggest that each year up to $20 \%$ of the United States population may be infected by influenza (Sullivan et al., 1993; Biggerstaff et al., 2014). The virus spreads easily from person to person via aerosol droplets (Hilleman, 2002; Taubenberger and Morens, 2008) and replicates in the upper and lower respiratory tract (Taubenberger and Morens, 2008). Commonly, in non-tropical regions, annual influenza epidemics occur during late autumn and winter. Although less frequent, tropical regions too suffer influenza epidemics, these generally coinciding with the rainy season (Cox and Subbarao, 2000; Biggerstaff et al., 2014).

There are three types of influenza virus, types A, B, and C, each differing in host range and pathogenicity (Taubenberger and Morens, 2008). Type A has been isolated from humans, avian, swine, horses, mink, dogs, seals, and ferrets (Jakeman et al., 1994; Taubenberger and Morens, 2008; Parrish et al., 2015), whilst type B has been isolated from humans, seals (Osterhaus et al., 2000) and ferrets (Jakeman et al., 1994), and type C from humans (Matsuzaki et al., 2002), swine and dogs (Youzbashi et al., 1996). Influenza A and B virions contain several structural antigens and three antigenic surface proteins; HA, NA, and M2/BM2 ion channels (Webster et al., 1992; Hampson and Mackenzie, 2006; Racaniello, 2009; Dormitzer et al., 2011). Influenza virus $C$ only expresses one antigenic surface protein, haemagglutinin-esterase-fusion (HEF), and thus stimulates a lesser immune reaction than types $\mathrm{A}$ or $\mathrm{B}$ (Taubenberger and Morens, 2008; Racaniello, 2009). Influenza A is the fastest to evolve, at a rate 2-3 times faster than B, whilst C is the slowest (Yamashita et al., 1988). Antigenic drift allows the influenza virus to escape immunity acquired through previous exposure or vaccination; thus influenza A causes more epidemics and pandemics than either influenza B or C (Hampson and Mackenzie, 2006; Taubenberger and Morens, 2008). Whilst influenza B causes periodic/yearly epidemics but not pandemics, influenza $\mathrm{C}$ viruses only cause relatively infrequent mild respiratory problems (Taubenberger and Morens, 2008). Throughout the past 300 years there have been 12 pandemics caused by influenza $A$; the most infamous being the 1918 'Spanish flu' pandemic (Taubenberger and Morens, 2008). In the years between 1933 and 1957 there were nine influenza A (H1N1) epidemics and five influenza B epidemics. The worst of all these epidemics was the 1935-1936 influenza B epidemic that resulted in at least 55,000 deaths. 
This was closely followed by the 1943-1944 influenza A (H1N1) epidemic which caused 53,000 deaths (Glezen, 1996). Evidently, although influenza B doesn't cause pandemics, it is still a cause for concern.

During an infection influenza virions attach to and enter host epithelial cells by the binding of viral HA to sialic acid on the host cell which instigates endocytosis and the movement of the virion into the cell within an endosome. The virus then uses/hijacks the host cells 'machinery' to replicate and transcribe viral RNA and produce more viral components (Samji, 2009). Progeny virions bud from the host cell, using the host cell membrane as a viral envelope, and go on to infect neighboring host cells (Nayak et al., 2009). As influenza infection develops the virus causes cell damage and death within the host's airways and upregulates the production of toxins, causing further destruction. Influenza cytotoxins for example causes necrosis of host cells (Conenello and Palese, 2007; Iverson et al., 2011). Influenza infection, particularly pandemic influenza infection, is known to generate an increased inflammation response within the host, as the body works to rapidly deliver immune cells to the site of infection. This inflammation is a response to the expression of cytokines and chemokines (de Jong et al., 2006; Kash et al., 2006; Kobasa et al., 2007; Rock and Kono, 2008). Virally induced decreased mucociliary activity, the dysfunction of immune cells and the reduction of phagocytosis reduces clearance of the virus from the host airways and the host's ability to fight the virus (Brundage, 2006; Wu et al., 2011; Cauley and Vella, 2015). In an attempt to limit and control infection, the host immune system kills infected host cells. It does this in several ways, including; the production of perforin by Natural Killer (NK) cells which creates lesions/pores in cell membranes resulting in the induction of apoptosis, apoptosis from tumour necrosis factor (TNF) and FasL and the production of reactive oxygen species from macrophages and neutrophils causing oxidation of cellular lipids, proteins and DNA resulting in cell dysfunction and death (Topham and Hewitt, 2009; Kash et al., 2014; Kash and Taubenberger, 2015). Of course viral infection and/or interference with host processes can cause and direct the pathway of cell death, as is the case for necrosis. Host cell death, whether apoptosis, necrosis or pyroptosis, impacts on the severity and outcome of influenza disease in a variety of ways. Virally induced death of immune cells assist in the evasion of host defenses and hinders the clearance of the virus promoting the development of infection. Studies have shown a $90 \%$ reduction of alveolar macrophages in mice within a week of influenza infection, and evidence of necrosis in the remaining macrophages (Robinson et al., 2015). Necrosis and pyroptosis are pro-inflammatory due to their role in the release of cytokines. These cell death pathways allow for the rapid release of intracellular contents, including any viral components, from the infected host cell promoting host inflammatory responses and the formation of a cytokine storm which causes host tissue damage (Cundell et al., 1995; Rock and Kono, 2008; Lamkanfi and Dixit, 2010; Cauley and Vella, 2015). Furthermore infection with some influenza subtypes, for instance $\mathrm{H} 1 \mathrm{~N} 1$ and $\mathrm{H} 5 \mathrm{~N} 1$, typically result in lymphopenia, a state of abnormally low levels of lymphocytes, which has been associated with higher viral load. de Jong et al. (2006) found influenza infection caused lower levels of cytotoxic $\mathrm{T}$ cell lymphocytes, which would therefore negatively affect acquired immunity (de Jong et al., 2006; Cunha et al., 2009). Where lymphopenia occurs, studies have shown a corresponding increase in macrophages. Supporting the evidence for the increase in macrophages is the significant increase in IP-10 (a chemokine secreted in response to gamma interferon (IFN $\gamma$ ) which activates macrophages), Interleukin-8 (IL-8, a chemokine which is produced by macrophages), IL-6 (in this case, a pro-inflammatory cytokine secreted by macrophages), and MCP-1 (a chemokine that recruits monocytes, a type of leukocyte that can differentiate into macrophages) (de Jong et al., 2006; Kobasa et al., 2007).

\section{INFLUENZA PANDEMICS SINCE THE LATE 1800's}

Influenza pandemics, generally characterized by the emergence of a novel influenza A against which little or no immunity exists within the global populace, are a cause of high mortality and morbidity and are a major financial burden (Glezen, 1996). Since the 1800's these pandemics have arisen from a number of countries, spreading across the globe (Figure 1). Detailed below and in Table 1 we have sought to describe some of the most significant influenza pandemics since the late 1800's to highlight the potential impact of influenza with respect to associations with bacterial infection.

\section{BACTERIAL CO-INFECTION AND SECONDARY INFECTIONS}

Laboratory, clinical and epidemiological research has made it abundantly clear that bacterial co/secondary infection can significantly increase the morbidity and mortality of viral infections (Gupta et al., 2008). Up to $75 \%$ of those infected with influenza that go on to acquire pneumonia, are confirmed to have bacterial co-infection (Zambon, 2001). Bacterial co/secondary infection of influenza infection appears to occur frequently. Studies have shown that up to $65 \%$ of laboratory confirmed cases of influenza infection exhibited bacterial co/secondary infection, although Klein et al. (2016) state that in the majority of the research included in their meta-analysis this figure ranged between 11 and 35\%. In the setting of an influenza epidemic or pandemic bacterial co/secondary infection can have devastating consequences, particularly in at-risk groups such as the immunocompromised/immunosuppressed. Immunosuppression is associated with more severe morbidity and a much higher risk of mortality from co/secondary bacterial infection (Rice et al., 2012). During the 2009 Swine influenza pandemic, there was an increase in hospital pneumonia cases as a result of secondary bacterial pneumonia, which was identified in $29-55 \%$ of mortalities (Centers for Disease Control and Prevention, 2009; Gill et al., 2010; Weinberger et al., 2012). 


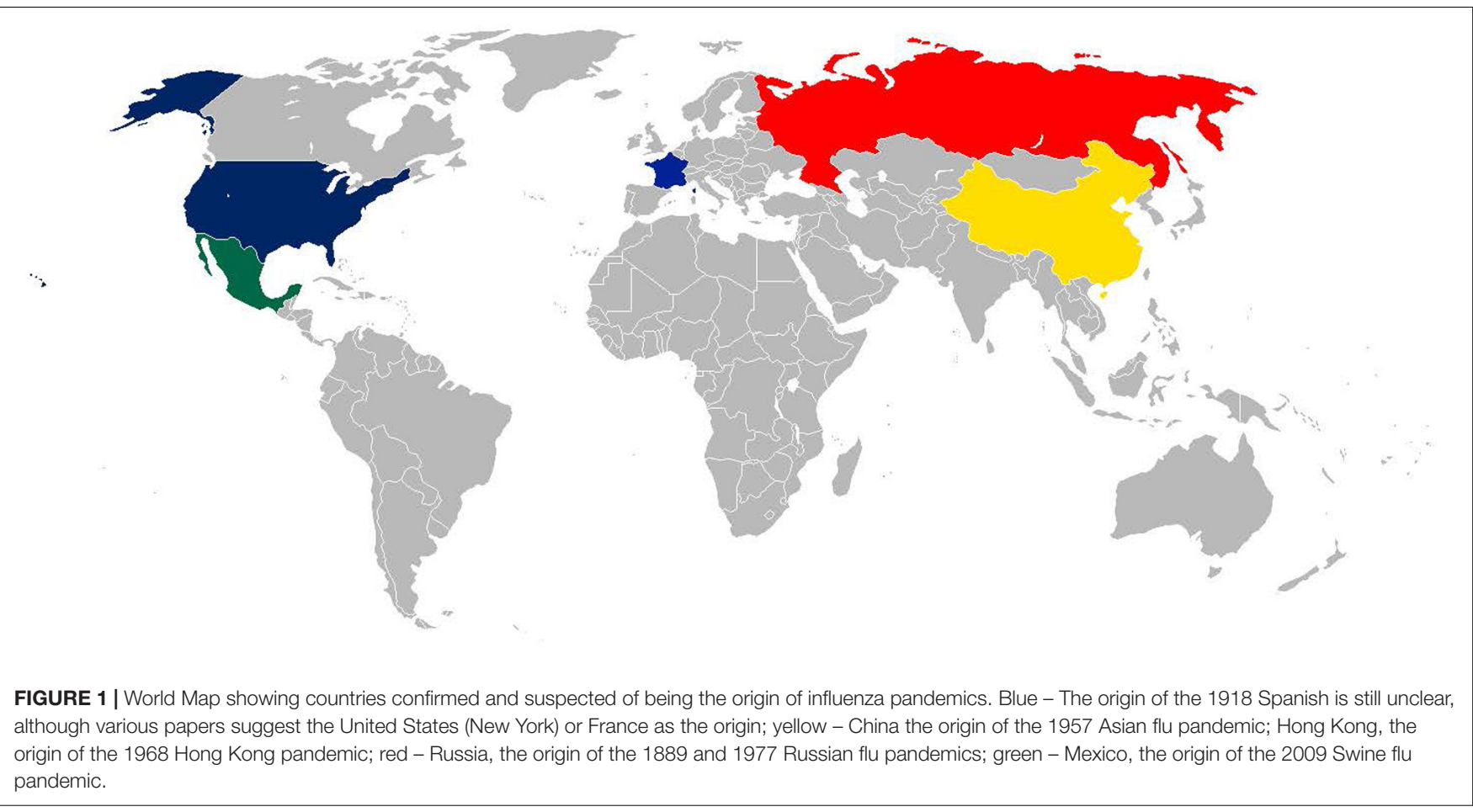

\section{PATHOBIONTS ASSOCIATED WITH CO/SECONDARY BACTERIAL INFECTION}

The upper respiratory tract has been shown to host a diverse microbiota, within which a number of bacterial pathobionts may be found, i.e., those bacterial species that can be pathogenic yet also harmlessly carried (Hooper et al., 2012; Cauley and Vella, 2015). Legionella pneumophila (Rizzo et al., 2010), Streptococcus pyogenes (Chertow and Memoli, 2013), Neisseria meningitidis, Moraxella catarrhalis, S. pneumoniae, H. influenzae, S. aureus (Dela Cruz and Wunderink, 2017), Pseudomonas aeruginosa as well as a number of other Streptococcus and Staphylococcus spp. (Yang et al., 2016a) have all been associated with co-infection of influenza. However, S. pneumoniae, H. influenzae, and S. aureus are the most commonly reported bacteria associated with $\mathrm{co} /$ secondary infections during influenza pandemics since the late 1800's.

\section{Streptococcus pneumoniae}

Streptococcus pneumoniae is the most common bacteria found in viral secondary bacterial infections, and is particularly associated with causing high mortality and morbidity during influenza epidemics and pandemics (Brundage, 2006; Joseph et al., 2013). S. pneumoniae is a Gram-positive diplococci and is the most common cause of community-acquired pneumonia and invasive disease, i.e., sepsis and meningitis worldwide, as well as less severe acute disease such as otitis media (Bridy-Pappas et al., 2005; McCullers et al., 2010). S. pneumoniae is grouped into $>97$ immunologically distinctive serotypes based on a polysaccharide capsule (Bentley et al., 2006; Park et al., 2007; Jin et al., 2009;
Calix and Nahm, 2010; Calix et al., 2012). A burden to public health in its' own right, the WHO has reported that diseases caused by $S$. pneumoniae resulted in approximately 826,000 deaths in 2000 alone (Pittet and Posfay-Barbe, 2012). A more recent study shows that there are 4 million cases of disease caused by $S$. pneumoniae and 22,000 deaths annually in the United States (Huang et al., 2011). The current public health impact of $S$. pneumoniae infection is reduced by vaccine policies, with, for example, PCV-13 and PPV-23 being used for children and adults, respectively, in the United Kingdom (Pittet and Posfay-Barbe, 2012).

Many studies have shown that influenza infection facilitates the acquisition, colonization and development of disease from S. pneumoniae in people of all ages (Shrestha et al., 2013; Grijalva et al., 2014; Siegel et al., 2014). This is partly due to $S$. pneumoniae's ability to catabolise sialic acid which is released from host cells and mucus by influenza's NA. Influenza infection also results in increased mucus production, further increasing the amount of metabolite available for S. pneumoniae. The NA produced by $S$. pneumoniae also assists in the release of sialic acid (Siegel et al., 2014). Mouse models support the concept that influenza facilitates the development of disease from $S$. pneumoniae; they have provided evidence that influenza infection enhances secondary $S$. pneumoniae pneumonia (McCullers and Rehg, 2002; McCullers and Bartmess, 2003). Wu et al. (2011), showed that co-infection of a virus and a bacterium can either occur from mixed viral bacterial infection, or from a viral infection being sequentially followed by a bacterial infection. Sequential bacterial infection normally occurs within a 7-day period of the viral infection. Influenza infections and successive S. pneumoniae infections result is a time and dose 
TABLE 1 | Details of significant influenza pandemics since the late 1800's.

\begin{tabular}{|c|c|c|c|c|}
\hline $\begin{array}{l}\text { Name of } \\
\text { pandemic }\end{array}$ & Year & Strain & Disease burden & Additional information \\
\hline
\end{tabular}

pandemic

Russian influenza 1889 pandemic

132,000 deaths in England, Wales and Ireland alone (Smith, 1995).

Spanish influenza 1918 pandemic

$\mathrm{A}(\mathrm{H} 1 \mathrm{N1}) \quad$ Caused 40-50 million deaths worldwide. India alone suffered 7 million deaths (Potter, 2001; Hilleman, 2002; Brundage, 2006; Michaelis et al., 2009).

Asian influenza 1957 pandemic $\quad 1958$
$\mathrm{A}(\mathrm{H} 2 \mathrm{~N} 2)$

1968 1969 influenza pandemic
A(H3N2) 1-2 million people died worldwide

$\mathrm{A}(\mathrm{H} 1 \mathrm{N1} 1) \quad$ Approximately 700,000 deaths

influenza $\quad 1978$

pandemic

Swine influenza 2009 pandemic (Michaelis et al., 2009). Overall 33,800 people died in the United States (Klimov et al., 1999) and England and Wales saw a 55\% increase in respiratory deaths in 1969 (Tillett et al., 1983). globally (Michaelis et al., 2009).

Although global death toll estimates vary [between 1.5 million (Gatherer, (Michaelis United States is accurately reported to have been 69, 800 (Klimov et al., 1999; Hilleman, 2002). By the end of the pandemic it is thought that there were 284,000 deaths worldwide (Chertow and Memoli, 2013).
The 1889 'Russian Flu' as the name suggests started in Russia and spread across Europe reaching North America in 1890. In only 4 months the infection had spread across all of Europe and the United States. The United Kingdom encountered four waves of disease and it is thought that at least one third of the adult population in England and Ireland suffered at least one bout of disease (Smith, 1995; Valleron et al., 2010).

Considered the most devastating influenza pandemic ever recorded, infecting $50 \%$ of the world's population. The origin of this pandemic is unclear as it appeared in North America, Asia, and Europe at roughly the same time (Taubenberger et al., 2001; Hilleman, 2002). Reports of disease and mortality were initially suppressed in many countries, included the United Kingdom, France and the United States, to ensure wartime efforts and morale weren't negatively affected. In Spain the press were able to print freely, meaning the first publicized cases were reported from Spain facilitating the nickname 'the Spanish flu' (Johnson, 2016; Peckham, 2016). In contrast to its name, it has been suggested that the pandemic started in France/mainland Europe and that it reached Spain from France (Reid et al., 2001; Trilla et al., 2008) although more recent papers suggest New York as the origin due to evidence of a pre-pandemic wave of the H1N1 virus (Olson et al., 2005). What is remarkable is how far the pandemic spread; the pandemic reached as far as the Alaskan wilderness to remote Pacific islands (Burnet and Clark, 1942; Taubenberger et al., 2001). The pandemic experienced a couple of waves; the first of which was relatively mild. The second wave, however, was far more lethal (Hilleman, 2002). The first outbreaks were reported in military camps as males responded to the call for troops in the spring and summer of 1918. A period of dormancy was then recorded toward the end of summer in America, but this was short lived as transmission picked up as schools reopened in September after the summer holidays (Glezen, 1996).

The pandemic affected 40-50\% of people worldwide (Potter, 2001), however, resulted in lot less mortality than the previous pandemic. This Asian influenza pandemic started in March 1957 in Southern China, where pigs, ducks, and humans live together closely. It reached Hong Kong in April, and then spread to Singapore, Taiwan, and Japan (Fukumi, 1959; Potter, 2001; Hilleman, 2002). The pandemic reached India, Australia, and Indonesia by May, Pakistan, Europe, North America, and the Middle East by June, South Africa, South America, New Zealand, and the Pacific Islands by July, and Central, West and East Africa, Eastern Europe, and the Caribbean by August (Dunn, 1958; Payne, 1958; Potter, 2001).

The 1968 Hong Kong pandemic started in July 1968 in Hong Kong and spread to the Southern hemisphere by June 1969 (Biggerstaff et al., 2014). The H3N2 virus was isolated and identified too late in the pandemic for vaccine intervention (Nakajima et al., 1978; Hilleman, 2002) so it was fortunate that in most countries, apart from the United States, the disease was mild (Cockburn et al., 1969). There are several proposed reasons for the reduced mortality of this compared to the Asian Flu. Firstly the N2 was seen in the Asian Flu so may have contributed some cross-reactive immunity to this H3N2 strain (Glezen, 1996). Although antibodies to NA do not prevent infection, they help to reduce the amount of newly formed virus released from infected cells (Couch et al., 1974; Glezen, 1996). Secondly, during the initial wave of this pandemic, the number of cases started to grow exponentially in December, at this point the school Christmas holidays began; it has been speculated that this removed an important susceptible population (Glezen, 1996). This pandemic was caused by a reappearance of $\mathrm{H} 1 \mathrm{~N} 1$, identical to that of the Spanish flu virus (Michaelis et al., 2009). The disease mainly affected those born after the late 1950's, so those who had not been exposed to the pandemic H1N1 strain that had circulated previously (Hilleman, 2002).

In early 2009, an influenza A H1N1 virus outbreak was initially identified in Mexico and then the United States (Michaelis et al., 2009). In June 2009 the WHO declared the outbreak a pandemic. Within 4 weeks the outbreak had spread to 41 countries, resulting in 11,034 confirmed cases and 85 deaths (Michaelis et al., 2009; Wang and Palese, 2009). Disease/symptoms were generally mild (Peiris et al., 2009) however, complications of the disease did result in hospitalization, particularly in at risk groups (Wang and Palese, 2009). 
TABLE 1 | Continued

\begin{tabular}{|c|c|c|c|c|}
\hline Name of pandemic & Year & Strain & Disease burden & Additional information \\
\hline & & & & $\begin{array}{l}\text { Unlike other pandemics and yearly epidemics, during this pandemic it was predominantly } \\
\text { children and young adults that were affected, particularly those aged 12-22 (Gill et al., 2010). } \\
\text { Overall this pandemic was relatively mild. It is thought that morbidity and mortality rates were } \\
\text { reduced due to three main factors. Firstly, the quick responses of various governments in terms } \\
\text { of school closures helped reduce the spread of the virus. Thousands of schools were shut } \\
\text { worldwide, including the United States and Mexico. Japan alone closed almost } 2000 \text { schools } \\
\text { (Wang and Palese, 2009; Jackson et al., 2014). Secondly, influenza A H1N1 strains have been } \\
\text { circulating amongst the human population for decades, therefore prior exposure could have } \\
\text { provided some degree of immunity against the } 2009 \text { pandemic strain. Lastly an important } \\
\text { pathogenicity factor, PB1-F2, was not present making the strain milder than those present in } \\
\text { previous pandemics (Wang and Palese, 2009). }\end{array}$ \\
\hline
\end{tabular}

dependent change in the host dendritic cells which produces enhanced inflammation. Berendt et al. (1975) inoculated squirrel monkeys with either influenza A, S. pneumoniae or influenza A and $S$. pneumoniae. Influenza alone caused minor illness such as mild tracheitis, with symptoms such as sneezing, coughing and fever (although some did develop bronchopneumonia) and had a $100 \%$ survival rate. S. pneumoniae again caused minor illness with a $100 \%$ survival rate. Co-infection of influenza A with S. pneumoniae resulted in severe morbidity with a $75 \%$ death rate within $40 \mathrm{~h}$, clear evidence of the consequences of co/secondary bacterial infection (Berendt et al., 1975). These findings are reflected in several other studies, with some even showing that co-infection may assist in the spreading of S. pneumoniae infection to the lower respiratory tract (Takase et al., 1999; Seki et al., 2004).

An additional mouse model of infection provided comparable results whilst comparing the effect of different $S$. pneumoniae serotypes on co-infection (Sharma-Chawla et al., 2016). More cases of pneumonia and bacteraemia were observed in mice infected with both influenza A and S. pneumoniae than in mice infected with these pathogens individually. This was the case for all S. pneumoniae serotypes tested. More virulent pneumococcal serotypes caused a greater burden of disease in both the coinfected mice and those infected with S. pneumoniae alone. The highly invasive pneumococcal serotype 4 caused pneumonia in $58 \%$ of mice and bacteraemia in $21 \%$ in a single infection model. When co-infecting with influenza these figures increased to 100 and $90 \%$ for pneumonia and bacteraemia, respectively. Mortality rates increased from $0 \%$ for individual infection to $79 \%$ during co-infection. In comparison, individual infection with a carrier strain (of lower invasive potential) of serotype 19F, caused pneumonia in $91 \%$ of cases and bacteraemia in $0 \%$. When co-infecting with influenza and 19F these figures increased to 100 and $33 \%$. Mortality rose from $0 \%$ during individual infection to 63\% during co-infection (Sharma-Chawla et al., 2016).

Pneumococcal vaccination has shown to ameliorate the risk of secondary bacterial pneumonia. During a vaccine efficacy study, the incidence of pneumonia in those with influenza reduced by $45 \%$ in groups vaccinated against $S$. pneumoniae (Madhi et al., 2007). However, whilst vaccine implementation has successfully reduced pneumococcal disease in a number of countries, lower levels of vaccine implementation in low and middle income countries coupled with fractional serotype coverage and increasing levels of antibiotic resistance, means the specter of influenza pandemic associated S. pneumoniae secondary infection remains a significant risk to global health.

\section{Haemophilus influenzae}

Haemophilus influenzae is another bacteria commonly found to co/secondarily infect viral infection, and has been associated with the complication of disease during influenza pandemics (Abrahams et al., 1919; Spooner et al., 1919; Brundage, 2006; Palacios et al., 2009). It is a Gram-negative fastidious coccobacillus. Typeable strains have a polysaccharide capsule and are categorized into six serotypes (A-F). H. influenzae serotype B was a major cause of invasive disease (Wenger, 1998; Murphy, 2003; Chin et al., 2005; Brouwer et al., 2010) although widespread implementation of the Hib vaccine has significantly reduced the burden of disease (Rosenstein and Perkins, 2000). Those $H$. influenzae that lack a capsule, denoted non-typeable H. influenzae (NTHi), remain a significant cause of bacterial meningitis, otitis media and exacerbations of chronic lung disease such as COPD worldwide (Langereis and de Jonge, 2015).

Various studies have shown the impact when $H$. influenzae $\mathrm{co} /$ secondarily infects with influenza, and some suggest a level of synergism. The effect of influenza and $H$. influenzae co-infection verses individual infection of both pathogens is tellingly different; Shope found that co-infection resulted in severe disease or death when on their own $H$. influenzae and influenza only caused mild infection or disease (Shope, 1931). More recently, Lee E.H. et al. (2010) undertook a similar study which provided comparable results and evidence that influenza and $\mathrm{H}$. influenzae co-infection produces more epithelial cell destruction than single infection with either pathogen (Lee L.N. et al., 2010). Furthermore, they found individual infection caused mild bronchiolitis within 4 days of initial infection, from which the host lung was able to recover. Conversely, co-infection caused bronchial necrosis, bronchial inflammation and bronchitis within the same time period or less, and led to further complication such as epithelial erosion (Lee L.N. et al., 2010). It is now commonly accepted that co-infection results in more severe morbidity and poorer clinical outcome than infection of influenza or $\mathrm{H}$. influenzae alone.

Further support of the impact of co-infection comes from Michaels et al. (1977), who dosed two groups of rats intranasally with $H$. influenzae with the intention of giving them meningitis. One group of rats were naive and the other had previously been 
dosed with influenza. In both groups $\sim 50 \%$ of the rats acquired meningitis, however, the naïve rats required a 100-fold larger dose of H. influenzae (Michaels et al., 1977).

As is the case for many bacterial and viral co-infections, mortality from $H$. influenzae and influenza co-infection is highly dependent on the timing of the introduction of the secondary microbe as well as density of bacterial colonization. Studies have shown that when influenza virus and $H$. influenzae are introduced at the same time there is no synergistic relationship. When $H$. influenzae is introduced 7 or more days after influenza there is again no synergistic relationship; however, high lethality is exhibited when $H$. influenzae and influenza are introduced 3 or 4 days apart (Lee L.N. et al., 2010).

\section{Staphylococcus aureus}

Staphylococcus aureus is a Gram-positive cocci that has been found to complicate influenza infection; increasingly so in more recent years/pandemics (Hers et al., 1958; Palacios et al., 2009). S. aureus is transiently carried in the nose of $30 \%$ of the population, whilst $20 \%$ of the population have persistent nasal colonization (Wertheim et al., 2005). Like H. influenzae and S. pneumoniae, $S$. aureus is an opportunistic pathogen and a major cause of bacteraemia (Wertheim et al., 2005; Tong et al., 2015). It is also a common cause of pneumonia (Kollef et al., 2005); specifically necrotising pneumonia that is caused by community acquired Methicillin-resistant Staphylococcus aureus (MRSA) and has a 30\% mortality rate (Murray et al., 2010). Necrotising pneumonia is highly associated with either the presence of Panton-Valentine leukocidin (PVL) or prior/co influenza infection (DeLeo and Musser, 2010). MRSA is a particularly problematic pathogen and concern for public health as it can be hard to treat due to its multidrug-resistant properties (Wu et al., 2005; Eom et al., 2014; Fishovitz et al., 2014).

Influenza infection has been shown to increase the adherence of $S$. aureus (as well as $H$. influenzae and S. pneumoniae) to host pharyngeal cells (Fainstein et al., 1980). In addition to this, mouse models have highlighted increased morbidity and mortality in mice that are pre-infected with influenza before they are exposed to $S$. aureus vs. those just exposed to $S$. aureus. Increased lung damage and bacterial density has also been shown (DeLeo and Musser, 2010; Lee M.H. et al., 2010; Iverson et al., 2011). Lee M.H. et al. (2010) showed that mice infected with low doses of influenza, low doses of $S$. aureus and high doses of $S$. aureus were able to survive. Those infected with high doses of influenza died within 4-7 days; however, all mice infected with a high dose of influenza and then a high dose $S$. aureus died within 2 days of bacterial exposure, showing how death can be accelerated by coinfection. When mice were infected with a low dose of influenza and then a high dose $S$. aureus they died at 7 days. The fact that the mice survived low influenza infection on its own, but could not survive co-infection with $S$. aureus shows the lethality of such co/secondary bacterial infection (Lee M.H. et al., 2010).

In an act of synergism, $S$. aureus infection may actually assist influenza infection by increasing the infectivity of influenza; when the virion is being moved into the host cell within an endosome the low $\mathrm{pH}$ in the endosome causes a conformational change to the $\mathrm{HA}\left[\mathrm{HA}_{(0)}\right]$ allowing it to be cleaved by host proteases into two subunits $\left[\mathrm{HA}_{(1)}\right.$ and $\left.\mathrm{HA}_{(2)}\right]$. This cleaving 'activates' the HA, mediating fusion between the virus and endosome membrane, ready for the opening of the M2 ion channel so the vRNP (viral ribonucleoproteins) can be released into the host cell where the viral RNA is replicated and transcribed. Several strains of $S$. aureus produce proteases that cleaves influenza HA; the more protease that is available, the more HA can be cleaved meaning more vRNP can get into host cells meaning overall more progeny virions (Tashiro et al., 1987; Steinhauer, 1999; Samji, 2009). This aspect contributes to the increased severity of disease caused by co-infection verses individual influenza infection. And although not all strains of $S$. aureus produce proteases that cleave influenza HA, the proteases they do produce indirectly enhance morbidity by causing host inflammatory responses which result in the production of host enzymes that are capable of cleaving HA (Tashiro et al., 1987).

\section{HISTORICAL EVIDENCE OF CO/SECONDARY BACTERIAL INFECTION DURING MAJOR INFLUENZA PANDEMICS}

\section{Spanish Influenza Pandemic}

The 1918 influenza pandemic was a result of influenza strain A (H1N1). It is considered the most devastating influenza pandemic ever recorded, infecting $50 \%$ of the world's population and resulting in approximately 40-50 million deaths worldwide. India alone suffered 7 million deaths (Potter, 2001; Hilleman, 2002; Brundage, 2006; Michaelis et al., 2009). The main groups of individuals affected by this pandemic were those aged $20-40$ years old, in addition to infants and those over 65. Ordinarily only young children and the elderly are the age groups most at risk from influenza, showing how distinctive pandemic strains can be (Potter, 2001). It is suggested that war time efforts meant that influenza easily spread through military camps, allowing the 20-40 years old age range to be more at risk than usual.

There are many published examples of co/secondary bacterial infections during the 1918 influenza pandemic, and pneumonia as a consequence of bacterial infection is estimated to have occurred in up to $95 \%$ of deaths during this pandemic (Morens et al., 2008). A majority of those deaths due to secondary S. pneumoniae infection (Brundage and Shanks, 2008; Morens et al., 2008). Many of the examples that detail co/secondary bacterial infection come from outbreaks within army camps. Within a 1-month period in 1918 at the military Camp Devens, a quarter of all troops were diagnosed with influenza. Of those infected, $17 \%$ developed pneumonia, of which $35 \%$ of cases were fatal. Out of 37 autopsies performed, 43\% were positive for pure growth of $H$. influenzae in at least one lobe of the lung. Blood culture revealed $65 \%$ had $S$. pneumoniae, $2.5 \%$ had $H$. influenzae and 1.3\% had S. aureus (Spooner et al., 1919; Brundage, 2006). This pattern of invasive bacterial co/secondary infection has also been documented for several other camps during the same year, including Camp Logan. Here 2,487 influenza-associated 
hospitalizations were recorded, $17 \%$ acquired pneumonia with $4 \%$ of these cases being fatal. Post-mortems found S. pneumoniae in the lungs of $44 \%$ and heart blood of 33\% (Hall et al., 1918; Brundage, 2006). At Camp Jackson, 17\% of influenza cases progressed to pneumonia with a further $31 \%$ of pneumonia cases proving fatal. Autopsies found S. pneumoniae to be the bacterial co-infection most associated with pneumonia, however, 155 of 312 lung cultures were positive for S. aureus (Michael, 1942; Brundage, 2006). At Camp Custer, 21\% of influenza cases progressed to pneumonia, of which $28 \%$ died. Sputum cultures proved the presence of S. pneumoniae in 26\% of cases. Further investigation found $28 \%$ of lung and blood cultures were positive for $S$. pneumoniae, again acting as supporting evidence of the invasive potential of such co-infections (Blanton and Irons, 1918; Brundage, 2006). Camp Fremont experienced 2418 hospitalizations, $17 \%$ had pneumonia of which $36 \%$ were fatal. Nasopharyngeal and sputum samples from 158 pneumonia cases found S. pneumoniae in $41 \%$ of cases, $H$. influenzae in $38 \%$, and other Streptococcus spp. in 29\% (Brem et al., 1918).

Further lung tissue from fatalities of this pandemic were re-examined in 1919; S. pyogenes longus was found in $36 \%$ of cases, S. pneumoniae in $29 \%$ of cases and $H$. influenzae in 25\% (Abrahams et al., 1919; Brundage, 2006). Additional postmortems of lung tissue suggest that at least $90 \%$ of samples showed evidence of bacterial infection (Oxford et al., 2002; Morens et al., 2008; Chien et al., 2009). Overall 95\% of deaths were due to co/secondary bacterial pneumonia (Opie et al., 1921; Morens et al., 2008).

Co-infection had also been reported as an issue prior to the official start of the pandemic. Influenza with secondary bacterial infection of S. pneumoniae (and other Streptococcus sp.), $H$. influenzae and/or Staphylococcus sp. was associated with major outbreaks of purulent bronchitis in 1916 and 1917 (Brundage, 2006; Joseph et al., 2013). Indeed in 1916-1917 British, Australian, Canadian, and American armed forces in England and France experienced an epidemic of purulent bronchitis. Out of 20 tested sputum specimens from a British army camp based in north France, 90\% presented with $H$. influenzae, $65 \%$ presented with S. pneumoniae, $25 \%$ with other Streptococcus spp. and 15\% with Staphylococcus spp. Out of the specimens positive for $H$. influenzae, many exhibited simultaneous $H$. influenzae and S. pneumoniae co-infection; with $H$. influenzae identified as the primary bacterial infector. S. pneumoniae infection first presented with low virulence, however, pathogenesis soon worsened, it has been suggested, as result of the symbiotic growth with $H$. influenzae (Brundage, 2006; Dennis Shanks et al., 2012). Of course it is known that there is a positive association between the colonization of $H$. influenzae and S. pneumoniae, and colonization is a prerequisite for disease, so the presence of such co-infection fits with current knowledge (Jacoby et al., 2007; Abdullahi et al., 2008).

\section{Asian Influenza Pandemic}

This pandemic affected $40-50 \%$ of people worldwide. The cause was influenza strain A (H2N2) (Potter, 2001). Although global death toll estimates vary [between 1.5 million (Gatherer, 2009) and 2-4 million (Michaelis et al., 2009)], the death toll in the United States is accurately reported to have been 69, 800 (Klimov et al., 1999; Hilleman, 2002). Post-mortem cultures show evidence of bacterial infection in up to $80 \%$ of all severe and fatal cases (Hers et al., 1958; Morens et al., 2008; Gill et al., 2010).

During this pandemic the United States, and many other countries, experienced an increase in hospitalization rates. A majority were due to pneumonia, predominantly caused by S. pneumoniae, H. influenzae, and S. aureus infection (Petersdorf et al., 1959). There are similar documented reports from the Netherlands; of the 148 deaths presumed to be from the Asian pandemic influenza strain that were examined fully, 75\% presented with bacterial pneumonia of which $15 \%$ were positive for S. pneumoniae and 59\% were positive for S. aureus (Hers et al., 1958).

Robertson et al. (1958) unveiled similar findings when investigating the hospitalization of 140 people suffering pneumonia at Sheffield City General Hospital in 1957. A majority showed evidence of influenza A infection; $27 \%$ of those had $\mathrm{co} /$ secondary infection of $S$. aureus (which had a $47 \%$ death rate), $15 \%$ S. pneumoniae and $4 \%$ H. influenzae, although this is likely to be an underestimation as many patients had already started taking antibiotics (Robertson et al., 1958).

\section{8-1969 Hong Kong Influenza Pandemic}

Worldwide 1-2 million people died during this pandemic which was caused by the influenza strain $\mathrm{A}(\mathrm{H} 3 \mathrm{~N} 2)$ (Michaelis et al., 2009). Although this is a lower death toll than engendered in previous pandemics, it is still an awfully high number of deaths. Overall 33,800 people died in the United States (Klimov et al., 1999) and the pandemic cost 3.9 billion dollars (Hilleman, 2002). In 1969, England and Wales saw a 55\% increase in respiratory deaths, of which co/secondary bacterial infection was shown to be a major contributor (Tillett et al., 1983).

Staphylococcal pneumonia in particular was a major source of complication to influenza infection. A hospital in Atlanta suffered a threefold increase in cases of Staphylococcal pneumonia during this pandemic. Staphylococcal infection caused 26\% of pneumonia cases during this period, and a high correlation was recognized between influenza infection and bacterial pneumonia (Schwarzmann et al., 1971). In addition, out of 79 cases of fatal influenza with pneumonia complications, $16 \%$ had bacterial co-infection with S. pneumoniae (6\%), S. pyogenes (5\%), and $S$. aureus (1\%) being the main causes. More than one of these bacteria were present in 4\% of cases (Schwarzmann et al., 1971; Metersky et al., 2012).

Another health care facility in the United States, the Mayo Clinic in Minnesota, also found S. aureus to be a major cause of complication. Of 129 adults diagnosed with pandemic influenza, pneumonia was established in $16 \%$, of which $40 \%$ of these cases (6\% of all 129 influenza cases) were fatal. S. aureus or $P$. aeruginosa bacterial infection was present in $75 \%$ of all fatal cases, indicating bacterial co/secondary infection was a major determinant of severe disease and death (Lindsay et al., 1970). 
In previous pandemics $S$. pneumoniae has been proposed as the major contributor of mortality and morbidity, however, during this 1968-1969 Hong Kong and the 1957 Asian influenza pandemic $S$. aureus clearly had a larger impact. This is possibly a reflection of increased antibiotic use and increased antibiotic resistance.

\section{Swine Influenza Pandemic}

Within 4 weeks this outbreak of influenza A(H1N1) had spread to 41 countries resulting in 11,034 confirmed cases and 85 deaths (Michaelis et al., 2009; Wang and Palese, 2009). By the end of the pandemic it is thought that there were 284,000 deaths worldwide, with Mexico and the United States being most severely affected (Chertow and Memoli, 2013). Unlike other pandemics and yearly epidemics, during this pandemic it was predominantly children and young adults that were affected, particularly those aged 12-22 (Gill et al., 2010). Influenza A (H1N1) strains have been circulating amongst the human population for many years therefore this prior exposure could have provided many adults with some degree of immunity against the 2009 pandemic strain, particularly older groups who were more likely exposed during previous pandemics.

Surveillance by the New York City Department of Health and Mental Hygiene has shown that during the 2009 Swine Flu Pandemic almost 30\% of the first 47 deaths showed invasive bacterial disease. $S$. pneumoniae was the most common causative agent identified (followed by S. pyogenes) (Lee E.H. et al., 2010). In the United Kingdom, of the 457 fatalities 68 were autopsied. Of these, $41 \%$ were shown to have complications associated with secondary bacterial infection, most commonly ( $25 \%$ of cases) due to S. pneumoniae (Lucas, 2010).

Further studies in the United States have reviewed 77 deaths during the period of May-August 2009 and found bacterial co-infection in almost $30 \%$ of cases; $46 \%$ of which were with S. pneumoniae, $9 \%$ with $S$. aureus and $1 \%$ with $H$. influenzae (Centers for Disease Control and Prevention, 2009). Studies based in Argentina produced similar evidence for the presence of bacterial infection, showing this wasn't just a localized trend. Palacios et al. (2009) examined nasopharyngeal swab samples from almost 200 cases of pandemic influenza. $H$. influenzae was found in 52\%, S. pneumoniae was found in $31 \%$ and S. aureus in $18 \%$ of samples. Although not the most common bacteria found, S. pneumoniae was the most strongly associated with severe disease (Palacios et al., 2009).

Additional research in pediatric intensive care units in the United States, investigated 838 critically ill children who were infected with pandemic influenza. Within $72 \mathrm{~h}$ of admission to the intensive care unit $33 \%$ exhibited bacterial co-infection; in $26 \%$ of these cases $S$. aureus was identified as the cause $(48 \%$ of which were MRSA), 5.5\% were positive for S. pneumoniae and 5\% were positive for $H$. influenzae. Bacteraemia was observed in 5\% of admissions, for which S. aureus was the main cause (Randolph et al., 2011). This study highlights how quickly co/secondary bacterial infection can become invasive particularly in at risk groups such as young children or the elderly. A point of concern is that almost half of the $S$. aureus were MRSA, and therefore inherently resistant to multiple antibiotics.
In another study of vulnerable and critically ill children in a pediatric intensive care unit in the United States, $51 \%$ of those with influenza infection had bacterial co/secondary infection. Of these $35 \%$ presented with $S$. aureus, $18 \%$ P. aeruginosa, $18 \%$ M. catarrhalis, 9\% NTHI, 6\% S. pneumoniae and 6\% Group A Streptococcus. Those with $S$. aureus showed more severe morbidity and were more likely to develop disseminated intravascular coagulation which leads to a compromised blood flow within body tissue and therefore tissue damage (Nguyen et al., 2012).

In a retrospective study of 50 patients who were infected during pandemic influenza, 28\% showed co/secondary bacterial infection (Dhanoa et al., 2011). Mycoplasma pneumoniae was found in $10 \%$, making it the most common co/secondary infecting bacteria. This was followed by $S$. aureus found in $6 \%$, K. pneumoniae and S. pneumoniae found in $4 \%$ and M. catarrhalis, P. aeruginosa, S. pyogenes, and Streptococcus agalactiae found in $2 \%$ of these patients (Dhanoa et al., 2011).

Moraxella catarrhalis is a bacteria of increasing importance being now acknowledged as the third most common cause of otitis media (OM), after S. pneumoniae and $H$. influenzae (Bluestone, 1986; Faden et al., 1994; Kilpi et al., 2001; Dupont et al., 2010) and the second most common cause of exacerbations in COPD, accounting for up to 4 million exacerbations per year in the United States alone (Murphy et al., 2005). M. catarrhalis is a cause of pneumonia (Berg and Bartley, 1987; Hager et al., 1987; Marchant, 1990; Verduin et al., 2002) and invasive disease such as bacteraemia (Ioannidis et al., 1995) and meningitis (Newing and Christie, 1947), with bacteraemia being a common complication of pneumonia, particularly in adults (Collazos et al., 1992; Ioannidis et al., 1995). Although this review has focused on S. pneumoniae, $H$. influenzae, and $S$. aureus, it has cited other bacteria seen as a source of co-infection during the various pandemics described. In early influenza pandemics such as the 1918 Spanish pandemic, M. catarrhalis rarely appears to be a noted cause of co-infection. However, in the 2009 pandemic it is seen in up to $18 \%$ of cases (Nguyen et al., 2012). We have therefore considered the importance of this. Data produced toward the end of the 1970's and throughout the 1980's demonstrated M. catarrhalis' potential to cause disease, however, before this $M$. catarrhalis was considered a non-pathogenic harmless commensal (McNeely et al., 1976; Johnson et al., 1981; Onofrio et al., 1981; McLeod et al., 1983; Feder and Garibaldi, 1984; Hager et al., 1987; Catlin, 1990). Therefore there are two possibilities to consider; perhaps $M$. catarrhalis wasn't present in early pandemics as a cause of co-infection and has become more of an issue in recent years; possibly as a result of vaccines, i.e., Hib and PCV, reducing the disease burden of other bacteria such as S. pneumonia and $H$. influenzae. Alternatively, we must consider that as $M$. catarrhalis was not considered a pathogen it was therefore missed or not commented upon prior to the 1980's. Retrospective studies may be able to address this. For example, autopsies from the 1918 pandemic were reviewed and it was found that S. pneumoniae was the most common co-infector, followed by $S$ hemolytic, S. aureus, and H. influenzae. 'Other bacteria' were also 
highlighted within which M. catarrhalis was grouped (Morens et al., 2008).

Another point of consideration are changes of methodology. Pre-1983 laboratories would only undertake bacterial culture, however, in 2009 more sensitive methodology, i.e., PCR were available and commonly used in laboratories worldwide. The use of sensitive methods such as PCR, may have increased the likelihood of $M$. catarrhalis being detected, and as a known respiratory pathogen it would have been tested for, where as previously it may not have been. Alternatively maybe PCR detects bacteria that may have been out grown/not shown on a culture plate?

In contrast to S. pneumoniae and $H$. influenzae little research has been undertaken looking at influenza and $M$. catarrhalis co-infection and the dynamics and mechanisms of such infection. This is therefore an area worthy of future research. $M$. catarrhalis has been highlighted as a frequent source of co-infection for influenza since the early 1980's (Klein et al., 2016). In the setting of a pandemic it may therefore have a major public health impact.

\section{FACTORS AFFECTING THE SEVERITY OF BACTERIAL CO/SECONDARY INFECTION}

As discussed above, co/secondary bacterial infection can result in a deterioration of clinical condition with more severe disease. The severity of co/secondary infection depends on multiple factors such as the strain of virus and serotype/strain of bacteria, the lag between viral infection and bacterial exposure and density of bacterial colonization (Lee L.N. et al., 2010; McCullers et al., 2010; Smith and McCullers, 2014).

\section{Virally Enhanced Colonization and Attachment of Bacteria}

It has become clear that influenza, as well as other upper respiratory tract viral infections, leads not only to a greater risk of infection from bacterial pathobionts but also an increased likelihood that an individual may become colonized with bacteria such as $S$. pneumoniae, $H$. influenzae and S. aureus (Hament et al., 1999; Hilleman, 2002). Plotkowski et al. (1986) found enhanced colonization and adherence of $S$. pneumoniae to the tracheal cells of mice when they were infected with influenza (Plotkowski et al., 1986). Other studies have intranasally inoculated ferrets with influenza, finding prior viral infection increases colonization and adherence of S. aureus (Sanford and Ramsay, 1987). Furthermore, poor disease outcome has been linked to lost lung repair function and loss of basal epithelial cells, including alveolar epithelial cells; which is associated with increased bacterial attachment and apoptosis (Kash et al., 2011). Wadowsky et al. (1995) conducted a study in which adult subjects were inoculated with influenza and then screened for bacterial colonization. After 6 days 15\% of the subjects were heavily colonized by S. pneumoniae (Wadowsky et al., 1995). Additionally, the effect of viral prevention methods further supports the idea of viruses predisposing a host to secondary bacterial infection (Peltola and McCullers, 2004; Lee et al., 2008). Studies have shown that influenza vaccination can reduce the occurrence of bacterial pneumonia (Fedson et al., 1993; Nichol et al., 1998).

\section{Viral Factors Implicated in Severity of Infection}

Research shows that influenza $\mathrm{A}$ is the type most commonly associated with co/secondary bacterial infection and subtypes with NA2 traditionally result in more severe infection (Peltola et al., 2005). Although reported less, influenza B has also been associated with severe bacterial co/secondary infection (Finelli et al., 2008; Aebi et al., 2010). Various factors are known to impact the severity of viral infection, which in turn increases the likelihood of bacterial co/secondary infections; these include the type of HA and NA surface antigen. As mentioned previously, HA mediates virion binding to the host cell via sialic acid receptors. Binding is followed by endocytosis and the movement of the virion into the host cell within an endosome (Samji, 2009). HA binds to sialylated glycans found on the surface of human epithelial cells; traditionally seasonal influenza A virus binds to $\alpha 2-6$ sialylated glycans on cells in the upper respiratory tract whereas the highly pathogenic avian H5N1 strain binds to $\alpha 2-3$ sialylated glycans on type 2 pneumocytes lining lung alveoli (Shinya et al., 2006). Clearly the type of HA impacts on the site and development of infection. The low $\mathrm{pH}$ in the endosome causes a conformational change to the HA allowing it to be cleaved, an important step in penetrating into the host cell. Therefore HA and the availability of appropriate host proteases are determinants of infectivity (Steinhauer, 1999; Samji, 2009). Interestingly non-pathogenic and mammalian influenza HA undergoes cleavage outside of the host cell where as highly pathogenic strains are cleaved inside host cells (Steinhauer, 1999). Another example of how the type of HA can make a difference to infection, and therefore the impact of an epi- or pandemic, is that traditionally trypsin-like protease cleaves influenza HA; however, some HA types (i.e., types 5 and 7) have the ability to acquire insertional mutations at the cleavage site which changes their recognition site in such a way that specificity is broadened so more proteases are recognized (Kash and Taubenberger, 2015).

Neuraminidase enables the release of newly formed progeny virions; by hydrolysing the sialic acid and detaching it from the HA the virion becomes liberated from the host cell (Zambon, 2001). To be truly effective the NA must be complementary and share the same receptor specificity as HA, so if the viral HA binds to $\alpha 2-3$ sialic acid then the NA should hydrolyse $\alpha 2-3$ sialic acid (Baum and Paulson, 1991).

The production of viral toxins that impact host cell integrity is another important factor in the development of co/secondary bacterial infection. Influenza A virus can produce a viral cytotoxin PB1-F2 (Conenello and Palese, 2007; Iverson et al., 2011) which plays a role in increasing inflammation and therefore host cell damage and bacterial adherence, increasing mortality and morbidity (Lee et al., 2016). It also helps reduce bacterial clearance, increasing the occurrence and severity of co/secondary bacterial infection, by causing cell death in host monocytes (Conenello and Palese, 2007; Iverson et al., 2011). 


\section{Molecular Co-pathogenesis}

Following bacterial colonization, disease develops due to specific characteristics of viral infection that facilitate bacterial adhesion and penetration (Selinger et al., 1981). Influenza produces NA, which increases adhesion of some bacterial species by removing sialic acid to expose host cell receptors (McCullers and Bartmess, 2003; Peltola and McCullers, 2004). Alternatively some bacteria, i.e., group B Streptococci, contain sialic acid which allows for direct binding to the viral HA expressed by influenza infected host cells (Okamoto et al., 2003; Peltola and McCullers, 2004). Damaged host cells, whether damaged directly by the virus or by inflammation and immune cell responses, provide additional adhesion sites allowing for increased bacterial adhesion. For example the exposure of apical receptors like integrins permit the adhesion of bacteria such as $S$. aureus and $P$. aeruginosa (Sanford et al., 1978; Davison and Sanford, 1981; Bucior et al., 2012; Smith and McCullers, 2014). In response to viral infection, host inflammatory responses may cause an up-regulation in the expression of host receptor molecules and other molecules that bacteria can use as a receptors (Hakansson et al., 1994; Peltola and McCullers, 2004). For example Cundell et al. (1995) showed an increased presentation of G-protein-coupled platelet-activating factor (PAF) receptor, which certain bacteria, i.e., S. pneumoniae, can utilize for cell attachment and colonization in endothelial cells (Cundell et al., 1995; van der Sluijs et al., 2010). In contrast it has been suggested that the PAF receptor does not affect initial bacterial adherence and colonization but is more involved with assisting bacterial transition/spread into the blood and thus the development of invasive disease (McCullers et al., 2008).

Influenza infection appears to prime the host airways for bacterial infection, whilst modifying and impairing immune responses in a number of ways (Joseph et al., 2013). Viral induced immunosuppression can allow for a bacterial super infection, as host immune responses can be suppressed when immunologic cells are impaired during influenza infection and immune cell dysfunction can reduce the host's ability to fight bacteria (Peltola and McCullers, 2004; Brundage, 2006; Wu et al., 2011). Many studies involving animal models have shown that influenza infection increases and prolongs bacterial growth, due to reduced macrophage accumulation and decreased bacterial clearance due to reduced phagocytic activity (Kleinerman et al., 1976; Wyde et al., 1989; Sun and Metzger, 2008). Additionally it has recently been shown that $S$. pneumoniae and influenza co-infection results in a reduction in the number of local alveolar macrophages, this due to increased death of these macrophages by apoptosis and necrosis (Sharma-Chawla et al., 2016). This reduction is likely to hinder bacterial clearance, hence the increased bacterial load found during co-infection during this study, and results in prolonged inflammatory response increasing morbidity. Even after influenza is cleared, S. pneumoniae bacterial clearance is affected. This study has highlighted some serotype dependent differences, suggesting different treatment programs would be beneficial for different serotypes. Evidence that it is worth further looking into co-infection of influenza with different serotypes of $S$. pneumoniae and other bacteria of interest (Sharma-Chawla et al., 2016). Impaired neutrophils have been shown to correlate with secondary bacterial infection in Chinchillas, due to the importance of phagocytosis during innate immunity (Abramson et al., 1981). Influenza infection is known to result in the production of IFN; pulmonary IFN $\gamma$ pro-inflammatory cytokines are produced by natural killer (NK) cells as part of innate immunity and by CD4 and CD8 NK T cells as part of adaptive immunity (Schoenborn and Wilson, 2007). They increase macrophage activation during innate immunity (Scott et al., 2004) however, during $\mathrm{T}$ cell responses to viral infection they have been shown to inhibit bacterial clearance from the respiratory system by macrophages. It is thought that as they assist in the induction of specific anti-influenza adaptive immunity they down regulate innate immunity. The resulting suppression of phagocytosis paves the way for successful bacterial infection (Sun and Metzger, 2008). Additionally, Type I IFNs inhibit interleukin 23 (IL-23) dependent induction of $\mathrm{T}$ helper cell 17 (Th17) immunity, and therefore there is a reduction in the levels of $\mathrm{CD} 4+\mathrm{T}$ cells and gamma delta $\mathrm{T}$ cells and hence a reduction in the production of IL-17 and IL-22, preventing the clearance of bacteria (Shahangian et al., 2009; Kudva et al., 2011; Mulcahy and McLoughlin, 2016). Robinson et al. (2013) have also shown that influenza A infection significantly decreased IL- $1 \beta$ production; IL-1 $\beta$ has been shown to play a role in Th17 polarization, therefore further hindering this pathway of immunity (Robinson et al., 2013). During co/secondary S. pneumoniae infection, type I IFNs have been shown to inhibit the production of specific chemokines (KC/CXCL1 and Mip2/CXCL2) resulting in an attenuated neutrophil response (Shahangian et al., 2009). Viral and bacterial co-infection of monocyte derived macrophages synergistically induces a pro-inflammatory response related to the type-I IFN and JAK-STAT signaling pathways (Hoffmann et al., 2016). Inflammation causes tissue damage, revealing more attachment sites for increased/developed bacterial infection. Co-infection also results in a synergistic increase in type II IFN (IFN $\gamma)$ when compared to individual infection of influenza or S. pneumoniae, CXCL10 (aka IFN $\gamma$-induced protein 10/IP-10) is secreted in response. IP-10 attracts various immune cells including activated $\mathrm{T}$ cells, monocytes and macrophages, therefore causing inflammation (Dufour et al., 2002; Hoffmann et al., 2016). Patients suffering severe pneumonia show significantly higher levels of IP-10 than those with minor cases of pneumonia. IP-10 is increased during $H$. influenzae and S. aureus co-infection as well, and like with S. pneumoniae, correlates with/highlights pneumonia etiology (Hoffmann et al., 2016). In addition, when $S$. pneumoniae successively co-infects with influenza it leads to severe clinical complications; partly due to an increase in apoptosis of dendritic cells, which therefore reduces $\mathrm{T}$ cell priming impairing the development of adaptive immunity. Influenza and S. pneumoniae infections can also lead to synergistic and non-synergistic dysregulation of cytokine responses (Wu et al., 2011).

As previously described influenza infection results in a reduction in the production of IL-17 and 22. IL-17 is important in the clearance of $S$. aureus by neutrophils (Archer et al., 2013). IL-22 in involved in controlling the production of antimicrobial peptides as well as staphylococcal ligand expression (Robinson et al., 2014; Mulcahy et al., 2016). In addition to 
this, influenza positively affects the colonization of $S$. aureus by causing increased type III- IFN expression, which alters the IL-22 responses impairing host expression of antimicrobial peptides (Mulcahy and McLoughlin, 2016). Distress signals, such as ATP and norepinephrine, produced by damaged influenza also have several effects on $S$. aureus; namely the instigation of biofilm dispersal which helps the spread of $S$. aureus into the lungs, assisting in the development of pneumonia and invasive disease (Mulcahy and McLoughlin, 2016).

Of course viral infection doesn't just benefit bacteria; several mechanisms of synergism between viruses and bacteria have been suggested. A number of studies have documented an increase in viral load as viral clearance is reduced during bacterial co-infection. It is, however, unclear whether this is from bacterial and viral cooperation/interactions or simply from bacteria burdening the host immune system resulting in the reduction of viral eradication. Therefore further research is required to develop our understanding of the interaction between bacteria and viruses within co-infection (Peltola and McCullers, 2004; Iverson et al., 2011; Smith and McCullers, 2014).

\section{CONCLUSION}

Viral infection aids bacterial infection in a number of ways, including unveiling/providing more sites for adhesion, impairing immune responses and causing cell and tissue destruction allowing for the spread of bacteria and development of invasive infection. Bacterial infection is then able to worsen clinical outcome and the severity of disease. Of course viral and bacterial co-infection can be mutually beneficial, further helping

\section{REFERENCES}

Abdullahi, O., Nyiro, J., Lewa, P., Slack, M., and Scott, J. A. (2008). The descriptive epidemiology of Streptococcus pneumoniae and Haemophilus influenzae nasopharyngeal carriage in children and adults in Kilifi district, Kenya. Pediatr. Infect. Dis. J. 27, 59-64. doi: 10.1097/INF.0b013e31814da70c

Abrahams, A., Hallows, N., and French, H. (1919). A further investigation into influenzo-pneumococcal and influenzo-streptococcal septicæmia: epidemic influenzal "pneumonia" of highly fatal type and its relation to "purulent bronchitis" Lancet 193, 1-11. doi: 10.1016/S0140-6736(01)22115-1

Abramson, J. S., Giebink, G. S., Mills, E. L., and Quie, P. G. (1981). Polymorphonuclear leukocyte dysfunction during influenza virus infection in chinchillas. J. Infect. Dis. 143, 836-845. doi: 10.1093/infdis/143.6.836

Aebi, T., Weisser, M., Bucher, E., Hirsch, H. H., Marsch, S., and Siegemund, M. (2010). Co-infection of influenza B and Streptococci causing severe pneumonia and septic shock in healthy women. BMC Infect. Dis. 10:308. doi: 10.1186/14712334- 10-308

Archer, N. K., Harro, J. M., and Shirtliff, M. E. (2013). Clearance of Staphylococcus aureus nasal carriage is $\mathrm{T}$ cell dependent and mediated through interleukin-17A expression and neutrophil influx. Infect. Immun. 81, 2070-2075. doi: 10.1128/ IAI.00084- 13

Baum, L. G., and Paulson, J. C. (1991). The N2 neuraminidase of human influenza virus has acquired a substrate specificity complementary to the hemagglutinin receptor specificity. Virology 180, 10-15. doi: 10.1016/0042-6822(91)90003-T

Bentley, S. D., Aanensen, D. M., Mavroidi, A., Saunders, D., Rabbinowitsch, E., Collins, M., et al. (2006). Genetic analysis of the capsular biosynthetic locus from all 90 pneumococcal serotypes. PLoS Genet. 2:e31. doi: 10.1371/journal. pgen.0020031 viral infection, which is bad news for public health. Although antibiotics can help reduce the impact of co/secondary bacterial infection, we still need to better understand the interactions between viruses, bacteria and their host, and to fully understand all mechanisms of disease. Particularly in light of increased antibiotic resistance and the ability of microbes to adapt and evade vaccine induced immunity.

The aim of this review was to emphasize the historical and continuing threat of influenza and to highlight the risk of bacterial co/secondary infection. Vaccines and antibiotics are readily available, however, with antibiotic resistance at an all-time high, vaccination is becoming even more vital in the fight against influenza epidemics and pandemics and the bacterial co/secondary infections commonly associated. It is important to examine the strains and types of bacteria and viruses being spread amongst and transmitted throughout the general public (or continue to in the case of influenza) to inform clinical treatment and development, particularly in the setting of an influenza epidemic or pandemic. As the threat from influenza is ever changing, we need to ensure we know what strains are circulating, which could cause issue and how they interact with other potential pathogens. This preparation also entails monitoring the changing epidemiology of bacterial pathogens associated with secondary infection, such as capsule switching which help S. pneumoniae evade immunity (Pai et al., 2005a,b).

\section{AUTHOR CONTRIBUTIONS}

DM, DC, and SC designed, planned and wrote the manuscript.

Berendt, R. F., Long, G. G., and Walker, J. S. (1975). Influenza alone and in sequence with pneumonia due to Streptococcus pneumoniae in the squirrel monkey. J. Infect. Dis. 132, 689-693. doi: 10.1093/infdis/132.6.689

Berg, R. A., and Bartley, D. L. (1987). Pneumonia associated with Branhamella catarrhalis in infants. Pediatr. Infect. Dis. J. 6, 569-573. doi: 10.1097/00006454198706000-00017

Biggerstaff, M., Cauchemez, S., Reed, C., Gambhir, M., and Finelli, L. (2014). Estimates of the reproduction number for seasonal, pandemic, and zoonotic influenza: a systematic review of the literature. BMC Infect. Dis. 14:480. doi: 10.1186/1471-2334-14-480

Blanton, W. B., and Irons, E. E. (1918). A recent epidemic of acute respiratory infection at camp custer, mich: preliminary laboratory report. J. Am. Med. Assoc. 71, 1988-1991. doi: 10.1001/jama.1918.26020500014006d

Bluestone, C. D. (1986). Otitis media and sinusitis in children. Role of Branhamella catarrhalis. Drugs 31(Suppl. 3), 132-141.

Brem, W. V., Bolling, G. E., and Casper, E. J. (1918). Pandemic “influenza” and secondary pneumonia at camp fremont, Calif. J. Am. Med. Assoc. 71, 2138-2144. doi: 10.1001/jama.1918.26020520007010b

Bridy-Pappas, A. E., Margolis, M. B., Center, K. J., and Isaacman, D. J. (2005). Streptococcus pneumoniae: description of the pathogen, disease epidemiology, treatment, and prevention. Pharmacotherapy 25, 1193-1212. doi: 10.1592/phco. 2005.25.9.1193

Brouwer, M. C., Tunkel, A. R., and van de Beek, D. (2010). Epidemiology, diagnosis, and antimicrobial treatment of acute bacterial meningitis. Clin. Microbiol. Rev. 23, 467-492. doi: 10.1128/CMR.00070-09

Brundage, J. F. (2006). Interactions between influenza and bacterial respiratory pathogens: implications for pandemic preparedness. Lancet Infect. Dis. 6, 303312. doi: 10.1016/S1473-3099(06)70466-2 
Brundage, J. F., and Shanks, G. D. (2008). Deaths from bacterial pneumonia during 1918-19 influenza pandemic. Emerg. Infect. Dis. 14, 1193-1199. doi: 10.3201/ eid1408.071313

Bucior, I., Pielage, J. F., and Engel, J. N. (2012). Pseudomonas aeruginosa pili and flagella mediate distinct binding and signaling events at the apical and basolateral surface of airway epithelium. PLoS Pathog. 8:e1002616. doi: 10.1371/ journal.ppat.1002616

Burnet, F. M., and Clark, E. (1942). Influenza: A Survey of the Last 50 Years in the Light of Modern Work on the Virus of Epidemic Influenza. London: Macmillan and coltd.

Calix, J. J., and Nahm, M. H. (2010). A new pneumococcal serotype, 11E, has a variably inactivated wcjE gene. J. Infect. Dis. 202, 29-38. doi: 10.1086/653123

Calix, J. J., Porambo, R. J., Brady, A. M., Larson, T. R., Yother, J., Abeygunwardana, C., et al. (2012). Biochemical, genetic, and serological characterization of two capsule subtypes among Streptococcus pneumoniae serotype 20 strains: discovery of a new pneumococcal serotype. J. Biol. Chem. 287, 27885-27894. doi: 10.1074/jbc.M112.380451

Catlin, B. W. (1990). Branhamella catarrhalis: an organism gaining respect as a pathogen. Clin. Microbiol. Rev. 3, 293-320. doi: 10.1128/CMR.3.4.293

Cauley, L. S., and Vella, A. T. (2015). Why is coinfection with influenza virus and bacteria so difficult to control? Discov. Med. 19, 33-40.

Centers for Disease Control and Prevention (2009). Bacterial co-infection in lung tissue specimens from fatal cases of 2009 pandemic influenza A (H1N1) United States, May-August 2009. Morb. Mortal. Wkly. Rep. 58, 1071-1074.

Chen, R., and Holmes, E. C. (2006). Avian influenza virus exhibits rapid evolutionary dynamics. Mol. Biol. Evol. 23, 2336-2341. doi: 10.1093/molbev/ msl102

Chertow, D. S., and Memoli, M. J. (2013). Bacterial coinfection in influenza: a grand rounds review. JAMA 309, 275-282. doi: 10.1001/jama.2012.194139

Chien, Y. W., Klugman, K. P., and Morens, D. M. (2009). Bacterial pathogens and death during the 1918 influenza pandemic. N. Engl. J. Med. 361, 2582-2583. doi: 10.1056/NEJMc0908216

Chin, C. L., Manzel, L. J., Lehman, E. E., Humlicek, A. L., Shi, L., Starner, T. D., et al. (2005). Haemophilus influenzae from patients with chronic obstructive pulmonary disease exacerbation induce more inflammation than colonizers. Am. J. Respir. Crit. Care Med. 172, 85-91. doi: 10.1164/rccm.200412-1687OC

Cockburn, W. C., Delon, P. J., and Ferreira, W. (1969). Origin and progress of the 1968-69 Hong Kong influenza epidemic. Bull. World Health Organ. 41, 345-348.

Collazos, J., de Miguel, J., and Ayarza, R. (1992). Moraxella catarrhalis bacteremic pneumonia in adults: two cases and review of the literature. Eur. J. Clin. Microbiol. Infect. Dis. 11, 237-240. doi: 10.1007/BF02098086

Conenello, G. M., and Palese, P. (2007). Influenza A virus PB1-F2: a small protein with a big punch. Cell Host Microbe 2, 207-209. doi: 10.1016/j.chom.2007. 09.010

Couch, R. B., Kasel, J. A., Gerin, J. L., Schulman, J. L., and Kilbourne, E. D. (1974). Induction of partial immunity to influenza by a neuraminidase-specific vaccine. J. Infect. Dis. 129, 411-420. doi: 10.1093/infdis/129.4.411

Cox, N. J., and Subbarao, K. (2000). Global epidemiology of influenza: past and present. Annu. Rev. Med. 51, 407-421. doi: 10.1146/annurev.med.51.1.407

Cundell, D. R., Gerard, N. P., Gerard, C., Idanpaan-Heikkila, I., and Tuomanen, E. I. (1995). Streptococcus pneumoniae anchor to activated human cells by the receptor for platelet-activating factor. Nature 377, 435-438. doi: 10.1038/ $377435 \mathrm{a} 0$

Cunha, B. A., Pherez, F. M., and Schoch, P. (2009). Diagnostic importance of relative lymphopenia as a marker of swine influenza $(\mathrm{H} 1 \mathrm{~N} 1)$ in adults. Clin. Infect. Dis. 49, 1454-1456. doi: 10.1086/644496

Daszak, P. (2012). Anatomy of a pandemic. Lancet 380, 1883-1884. doi: 10.1016/ S0140-6736(12)61887-X

Davison, V. E., and Sanford, B. A. (1981). Adherence of Staphylococcus aureus to influenza A virus-infected madin-darby canine kidney cell cultures. Infect. Immun. 32, 118-126.

de Jong, M. D., Simmons, C. P., Thanh, T. T., Hien, V. M., Smith, G. J., Chau, T. N., et al. (2006). Fatal outcome of human influenza A (H5N1) is associated with high viral load and hypercytokinemia. Nat. Med. 12, 1203-1207. doi: $10.1038 / \mathrm{nm} 1477$

Dela Cruz, C. S., and Wunderink, R. G. (2017). Respiratory Viral and Atypical Pneumonia in Adults. Amsterdam: Elsevier.
DeLeo, F. R., and Musser, J. M. (2010). Axis of coinfection evil. J. Infect. Dis. 201, 488-490. doi: 10.1086/650304

Dennis Shanks, G., Mackenzie, A., Waller, M., and Brundage, J. F. (2012). Relationship between "purulent bronchitis" in military populations in Europe prior to 1918 and the 1918-1919 influenza pandemic. Influenza Other Respir. Viruses 6, 235-239. doi: 10.1111/j.1750-2659.2011. 00309.x

Dhanoa, A., Fang, N. C., Hassan, S. S., Kaniappan, P., and Rajasekaram, G. (2011). Epidemiology and clinical characteristics of hospitalized patients with pandemic influenza A (H1N1) 2009 infections: the effects of bacterial coinfection. Virol. J. 8:501. doi: 10.1186/1743-422X-8-501

Dormitzer, P. R., Galli, G., Castellino, F., Golding, H., Khurana, S., Del Giudice, G., et al. (2011). Influenza vaccine immunology. Immunol. Rev. 239, 167-177. doi: 10.1111/j.1600-065X.2010.00974.x

Dufour, J. H., Dziejman, M., Liu, M. T., Leung, J. H., Lane, T. E., and Luster, A. D. (2002). IFN-gamma-inducible protein 10 (IP-10; CXCL10)-deficient mice reveal a role for IP-10 in effector T cell generation and trafficking. J. Immunol. 168, 3195-3204. doi: 10.4049/jimmunol.168.7.3195

Dunn, F. L. (1958). Pandemic influenza in 1957; review of international spread of new Asian strain. J. Am. Med. Assoc. 166, 1140-1148. doi: 10.1001/jama.1958. 02990100028006

Dupont, D., Mahjoub-Messai, F., Francois, M., Doit, C., Mariani-Kurkdjian, P., Bidet, P., et al. (2010). Evolving microbiology of complicated acute otitis media before and after introduction of the pneumococcal conjugate vaccine in France. Diagn. Microbiol. Infect. Dis. 68, 89-92. doi: 10.1016/j.diagmicrobio.2010. 04.012

Eldin, C., Melenotte, C., Mediannikov, O., Ghigo, E., Million, M., Edouard, S., et al. (2017). From Q fever to Coxiella burnetii infection: a paradigm change. Clin. Microbiol. Rev 30, 115-190. doi: 10.1128/CMR.00045-16

Eom, S.-H., Lee, D.-S., Jung, Y.-J., Park, J.-H., Choi, J.-I., Yim, M.-J., et al. (2014). The mechanism of antibacterial activity of phlorofucofuroeckol-A against methicillin-resistant Staphylococcus aureus. Appl. Microbiol. Biotechnol. 98, 9795-9804. doi: 10.1007/s00253-014-6041-8

Faden, H., Harabuchi, Y., and Hong, J. J. (1994). Epidemiology of Moraxella catarrhalis in children during the first 2 years of life: relationship to otitis media. J. Infect. Dis. 169, 1312-1317. doi: 10.1093/infdis/169.6. 1312

Fainstein, V., Musher, D. M., and Cate, T. R. (1980). Bacterial adherence to pharyngeal cells during viral infection. J. Infect. Dis. 141, 172-176. doi: 10.1093/ infdis/141.2.172

Feder, H. M. Jr., and Garibaldi, R. A. (1984). The significance of nongonococcal, nonmeningococcal Neisseria isolates from blood cultures. Rev. Infect. Dis. 6, 181-188. doi: 10.1093/clinids/6.2.181

Fedson, D. S., Wajda, A., Nicol, J. P., Hammond, G. W., Kaiser, D. L., and Roos, L. L. (1993). Clinical effectiveness of influenza vaccination in Manitoba. JAMA 270, 1956-1961. doi: 10.1001/jama.1993.03510160074032

Finelli, L., Fiore, A., Dhara, R., Brammer, L., Shay, D. K., Kamimoto, L., et al. (2008). Influenza-associated pediatric mortality in the United States: increase of Staphylococcus aureus coinfection. Pediatrics 122, 805-811. doi: 10.1542/peds. 2008- 1336

Fishovitz, J., Rojas-Altuve, A., Otero, L. H., Dawley, M., Carrasco-López, C., Chang, M., et al. (2014). Disruption of allosteric response as an unprecedented mechanism of resistance to antibiotics. J. Am. Chem. Soc. 136, 9814-9817. doi: $10.1021 /$ ja5030657

Fukumi, H. (1959). Summary report on the Asian influenza epidemic in Japan, 1957. Bull. World Health Organ. 20, 187-198.

Gatherer, D. (2009). The $2009 \mathrm{H} 1 \mathrm{N1}$ influenza outbreak in its historical context. J. Clin. Virol. 45, 174-178. doi: 10.1016/j.jcv.2009.06.004

Gill, J. R., Sheng, Z. M., Ely, S. F., Guinee, D. G., Beasley, M. B., Suh, J., et al. (2010). Pulmonary pathologic findings of fatal 2009 pandemic influenza A/H1N1 viral infections. Arch. Pathol. Lab. Med. 134, 235-243. doi: 10.1043/1543-2165-134. 2.235

Glezen, W. P. (1996). Emerging infections: pandemic influenza. Epidemiol. Rev. 18, 64-76. doi: 10.1093/oxfordjournals.epirev.a017917

Grijalva, C. G., Griffin, M. R., Edwards, K. M., Williams, J. V., Gil, A. I., Verastegui, H., et al. (2014). The role of influenza and parainfluenza infections in nasopharyngeal pneumococcal acquisition among young children. Clin. Infect. Dis. 58, 1369-1376. doi: 10.1093/cid/ciu148 
Gupta, R. K., George, R., and Nguyen-Van-Tam, J. S. (2008). Bacterial pneumonia and pandemic influenza planning. Emerg. Infect. Dis. 14, 1187-1192. doi: 10.3201/eid1408.070751

Hager, H., Verghese, A., Alvarez, S., and Berk, S. L. (1987). Branhamella catarrhalis respiratory infections. Rev. Infect. Dis. 9, 1140-1149. doi: 10.1093/clinids/9.6. 1140

Hakansson, A., Kidd, A., Wadell, G., Sabharwal, H., and Svanborg, C. (1994). Adenovirus infection enhances in vitro adherence of Streptococcus pneumoniae. Infect. Immun. 62, 2707-2714.

Hall, J. N., Stone, M. C., and Simpson, J. C. (1918). The epidemic of pneumonia following influenza at Camp Logan, Texas: preliminary report. J. Am. Med. Assoc. 71, 1986-1987. doi: 10.1001/jama.1918.26020500012006c

Hament, J.-M., Kimpen, J. L. L., Fleer, A., and Wolfs, T. F. W. (1999). Respiratory viral infection predisposing for bacterial disease: a concise review. FEMS Immunol. Med. Microbiol. 26, 189-195. doi: 10.1111/j.1574-695X.1999.tb0 1389.x

Hampson, A. W., and Mackenzie, J. S. (2006). The influenza viruses. Med. J. Aust. 185, S39-S43.

Hers, J. F., Masurel, N., and Mulder, J. (1958). Bacteriology and histopathology of the respiratory tract and lungs in fatal Asian influenza. Lancet 2, 1141-1143. doi: 10.1016/S0140-6736(58)92404-8

Hilleman, M. R. (2002). Realities and enigmas of human viral influenza: pathogenesis, epidemiology and control. Vaccine 20, 3068-3087. doi: 10.1016/ S0264-410X(02)00254-2

Hoffmann, J., Machado, D., Terrier, O., Pouzol, S., Messaoudi, M., Basualdo, W., et al. (2016). Viral and bacterial co-infection in severe pneumonia triggers innate immune responses and specifically enhances IP-10: a translational study. Sci. Rep. 6:38532. doi: 10.1038/srep38532

Holland, J., Spindler, K., Horodyski, F., Grabau, E., Nichol, S., and VandePol, S. (1982). Rapid evolution of RNA genomes. Science 215, 1577-1585. doi: 10.1126/ science.7041255

Hooper, L. V., Littman, D. R., and Macpherson, A. J. (2012). Interactions between the microbiota and the immune system. Science 336, 1268-1273. doi: 10.1126/ science. 1223490

Houser, K., and Subbarao, K. (2015). Influenza vaccines: challenges and solutions. Cell Host Microbe 17, 295-300. doi: 10.1016/j.chom.2015.02.012

Huang, S. S., Johnson, K. M., Ray, G. T., Wroe, P., Lieu, T. A., Moore, M. R., et al. (2011). Healthcare utilization and cost of pneumococcal disease in the United States. Vaccine 29, 3398-3412. doi: 10.1016/j.vaccine.2011.02.088

Ioannidis, J. P., Worthington, M., Griffiths, J. K., and Snydman, D. R. (1995). Spectrum and significance of bacteremia due to Moraxella catarrhalis. Clin. Infect. Dis. 21, 390-397. doi: 10.1093/clinids/21.2.390

Iverson, A. R., Boyd, K. L., McAuley, J. L., Plano, L. R., Hart, M. E., and McCullers, J. A. (2011). Influenza virus primes mice for pneumonia from Staphylococcus aureus. J. Infect. Dis. 203, 880-888. doi: 10.1093/infdis/jiq113

Jackson, C., Mangtani, P., Hawker, J., Olowokure, B., and Vynnycky, E. (2014). The effects of school closures on influenza outbreaks and pandemics: systematic review of simulation studies. PLoS ONE 9:e97297. doi: 10.1371/journal.pone. 0097297

Jacoby, P., Watson, K., Bowman, J., Taylor, A., Riley, T. V., Smith, D. W., et al. (2007). Modelling the co-occurrence of Streptococcus pneumoniae with other bacterial and viral pathogens in the upper respiratory tract. Vaccine 25, 2458-2464. doi: 10.1016/j.vaccine.2006.09.020

Jakeman, K. J., Tisdale, M., Russell, S., Leone, A., and Sweet, C. (1994). Efficacy of 2'-deoxy-2'-fluororibosides against influenza A and B viruses in ferrets. Antimicrob. Agents Chemother. 38, 1864-1867. doi: 10.1128/AAC.38.8.1864

Jin, P., Kong, F., Xiao, M., Oftadeh, S., Zhou, F., Liu, C., et al. (2009). First report of putative Streptococcus pneumoniae serotype 6D among nasopharyngeal isolates from Fijian children. J. Infect. Dis. 200, 1375-1380. doi: 10.1086/606118

Johnson, B. (2016). The Spanish Flu Pandemic of 1918. Available at: http://www.historic-uk.com/HistoryUK/HistoryofBritain/The-SpanishFlu-pandemic-of-1918/

Johnson, M. A., Drew, W. L., and Roberts, M. (1981). Branhamella (Neisseria) catarrhalis-a lower respiratory tract pathogen? J. Clin. Microbiol. 13, 1066-1069.

Jones, K. E., Patel, N. G., Levy, M. A., Storeygard, A., Balk, D., Gittleman, J. L., et al. (2008). Global trends in emerging infectious diseases. Nature 451, 990-993. doi: $10.1038 /$ nature 06536
Joseph, C., Togawa, Y., and Shindo, N. (2013). Bacterial and viral infections associated with influenza. Influenza Other Respir. Viruses 7(Suppl. 2), 105-113. doi: 10.1111/irv.12089

Karesh, W. B., Dobson, A., Lloyd-Smith, J. O., Lubroth, J., Dixon, M. A., Bennett, M., et al. (2012). Ecology of zoonoses: natural and unnatural histories. Lancet 380, 1936-1945. doi: 10.1016/S0140-6736(12)61678-X

Kash, J. C., and Taubenberger, J. K. (2015). The role of viral, host, and secondary bacterial factors in influenza pathogenesis. Am. J. Pathol. 185, 1528-1536. doi: 10.1016/j.ajpath.2014.08.030

Kash, J. C., Tumpey, T. M., Proll, S. C., Carter, V., Perwitasari, O., Thomas, M. J., et al. (2006). Genomic analysis of increased host immune and cell death responses induced by 1918 influenza virus. Nature 443, 578-581. doi: 10.1038/ nature 05181

Kash, J. C., Walters, K. A., Davis, A. S., Sandouk, A., Schwartzman, L. M., Jagger, B. W., et al. (2011). Lethal synergism of 2009 pandemic H1N1 influenza virus and Streptococcus pneumoniae coinfection is associated with loss of murine lung repair responses. MBio 2:e00172-11. doi: 10.1128/mBio. 00172-11

Kash, J. C., Xiao, Y., Davis, A. S., Walters, K. A., Chertow, D. S., Easterbrook, J. D., et al. (2014). Treatment with the reactive oxygen species scavenger EUK-207 reduces lung damage and increases survival during 1918 influenza virus infection in mice. Free Radic. Biol. Med. 67, 235-247. doi: 10.1016/j. freeradbiomed.2013.10.014

Kilpi, T., Herva, E., Kaijalainen, T., Syrjanen, R., and Takala, A. K. (2001). Bacteriology of acute otitis media in a cohort of Finnish children followed for the first two years of life. Pediatr. Infect. Dis. J. 20, 654-662. doi: 10.1097/ 00006454-200107000-00004

Klein, E. Y., Monteforte, B., Gupta, A., Jiang, W., May, L., Hsieh, Y. H., et al. (2016). The frequency of influenza and bacterial coinfection: a systematic review and meta-analysis. Influenza Other Respir. Viruses 10, 394-403. doi: 10.1111/irv. 12398

Kleinerman, E. S., Daniels, C. A., Polisson, R. P., and Snyderman, R. (1976). Effect of virus infection on the inflammatory response. Depression of macrophage accumulation in influenza-infected mice. Am. J. Pathol. 85, 373-382.

Klimov, A., Simonsen, L., Fukuda, K., and Cox, N. (1999). Surveillance and impact of influenza in the United States. Vaccine 17(Suppl. 1), S42-S46. doi: 10.1016/ S0264-410X(99)00104-8

Kobasa, D., Jones, S. M., Shinya, K., Kash, J. C., Copps, J., Ebihara, H., et al. (2007). Aberrant innate immune response in lethal infection of macaques with the 1918 influenza virus. Nature 445, 319-323. doi: 10.1038/nature05495

Kollef, M. H., Shorr, A., Tabak, Y. P., Gupta, V., Liu, L. Z., and Johannes, R. S. (2005). Epidemiology and outcomes of health-care-associated pneumonia: results from a large US database of culture-positive pneumonia. Chest 128, 3854-3862. doi: 10.1378/chest.128.6.3854

Kudva, A., Scheller, E. V., Robinson, K. M., Crowe, C. R., Choi, S. M., Slight, S. R., et al. (2011). Influenza A inhibits Th17-mediated host defense against bacterial pneumonia in mice. J. Immunol. 186, 1666-1674. doi: 10.4049/jimmunol. 1002194

Lamkanfi, M., and Dixit, V. M. (2010). Manipulation of Host Cell Death Pathways during Microbial Infections. Cell Host Microbe 8, 44-54. doi: 10.1016/j.chom. 2010.06.007

Langereis, J. D., and de Jonge, M. I. (2015). Invasive disease caused by nontypeable Haemophilus influenzae. Emerg. Infect. Dis. 21, 1711-1718. doi: 10.3201/ eid2110.150004

Lee, E. H., Wu, C., Lee, E. U., Stoute, A., Hanson, H., Cook, H. A., et al. (2010). Fatalities associated with the $2009 \mathrm{H} 1 \mathrm{~N} 1$ influenza A virus in New York city. Clin. Infect. Dis. 50, 1498-1504. doi: 10.1086/652446

Lee, L. N., Dias, P., Han, D., Yoon, S., Shea, A., Zakharov, V., et al. (2010). A mouse model of lethal synergism between influenza virus and Haemophilus influenzae. Am. J. Pathol. 176, 800-811. doi: 10.2353/ajpath.2010.090596

Lee, M. H., Arrecubieta, C., Martin, F. J., Prince, A., Borczuk, A. C., and Lowy, F. D. (2010). A postinfluenza model of Staphylococcus aureus pneumonia. J. Infect. Dis. 201, 508-515. doi: 10.1086/650204

Lee, P. H., Bird, N., MacKenzie-Kludas, C., Mansell, A., Kedzierska, K., Brown, L., et al. (2016). Induction of memory cytotoxic $T$ cells to influenza $A$ virus and subsequent viral clearance is not modulated by PB1-F2-dependent inflammasome activation. Immunol. Cell Biol. 94, 439-446. doi: 10.1038/icb. 2015.115 
Lee, S. E., Eick, A., Bloom, M. S., and Brundage, J. F. (2008). Influenza immunization and subsequent diagnoses of group A streptococcus-illnesses among U.S. Army trainees, 2002-2006. Vaccine 26, 3383-3386. doi: 10.1016/j. vaccine.2008.04.041

Li, Q., Sun, X., Li, Z., Liu, Y., Vavricka, C. J., Qi, J., et al. (2012). Structural and functional characterization of neuraminidase-like molecule N10 derived from bat influenza A virus. Proc. Natl. Acad. Sci. U.S.A. 109, 18897-18902. doi: 10.1073/pnas.1211037109

Lindsay, M. I. Jr., Herrmann, E. C. Jr., Morrow, G. W. Jr., and Brown, A. L. Jr. (1970). Hong kong influenza: clinical, microbiologic, and pathologic features in 127 cases. JAMA 214, 1825-1832. doi: 10.1001/jama.1970.03180100019004

Lozano, R., Naghavi, M., Foreman, K., Lim, S., Shibuya, K., Aboyans, V., et al. (2012). Global and regional mortality from 235 causes of death for 20 age groups in 1990 and 2010: a systematic analysis for the Global Burden of Disease Study 2010. Lancet 380, 2095-2128. doi: 10.1016/S0140-6736(12)61728-0

Lucas, S. (2010). Predictive clinicopathological features derived from systematic autopsy examination of patients who died with A/H1N1 influenza infection in the UK 2009-10 pandemic. Health Technol. Assess. 14, 83-114. doi: 10.3310/ hta14550-02

Madhi, S. A., Adrian, P., Kuwanda, L., Cutland, C., Albrich, W. C., and Klugman, K. P. (2007). Long-term effect of pneumococcal conjugate vaccine on nasopharyngeal colonization by Streptococcus pneumoniae and associated interactions with Staphylococcus aureus and Haemophilus influenzae colonization in HIV-Infected and HIV-uninfected children. J. Infect. Dis. 196, 1662-1666. doi: 10.1086/522164

Marchant, C. D. (1990). Spectrum of disease due to Branhamella catarrhalis in children with particular reference to acute otitis media. Am. J. Med. 88, 15S-19S. doi: 10.1016/0002-9343(90)90255-c

Matsuzaki, Y., Sugawara, K., Mizuta, K., Tsuchiya, E., Muraki, Y., Hongo, S., et al. (2002). Antigenic and genetic characterization of influenza $C$ viruses which caused two outbreaks in Yamagata City, Japan, in 1996 and 1998. J. Clin. Microbiol. 40, 422-429. doi: 10.1128/JCM.40.2.422-429.2002

McCullers, J. A., and Bartmess, K. C. (2003). Role of neuraminidase in lethal synergism between influenza virus and Streptococcus pneumoniae. J. Infect. Dis. 187, 1000-1009. doi: 10.1086/368163

McCullers, J. A., Iverson, A. R., McKeon, R., and Murray, P. J. (2008). The platelet activating factor receptor is not required for exacerbation of bacterial pneumonia following influenza. Scand. J. Infect. Dis. 40, 11-17. doi: 10.1080/ 00365540701477568

McCullers, J. A., McAuley, J. L., Browall, S., Iverson, A. R., Boyd, K. L., and Henriques Normark, B. (2010). Influenza enhances susceptibility to natural acquisition of and disease due to Streptococcus pneumoniae in ferrets. J. Infect. Dis. 202, 1287-1295. doi: 10.1086/656333

McCullers, J. A., and Rehg, J. E. (2002). Lethal synergism between influenza virus and Streptococcus pneumoniae: characterization of a mouse model and the role of platelet-activating factor receptor. J. Infect. Dis. 186, 341-350. doi: 10.1086/ 341462

McLeod, D. T., Ahmad, F., Power, J. T., Calder, M. A., and Seaton, A. (1983). Bronchopulmonary infection due to Branhamella catarrhalis. Br. Med. J. (Clin. Res. Ed) 287, 1446-1447. doi: 10.1136/bmj.287.6403.1446

McNeely, D. J., Kitchens, C. S., and Kluge, R. M. (1976). Fatal Neisseria (Branhamella) catarrhalis pneumonia in an immunodeficient host. Am. Rev. Respir. Dis. 114, 399-402.

Metersky, M. L., Masterton, R. G., Lode, H., File, T. M. Jr., and Babinchak, T. (2012). Epidemiology, microbiology, and treatment considerations for bacterial pneumonia complicating influenza. Int. J. Infect. Dis. 16, e321-31. doi: 10.1016/ j.ijid.2012.01.003

Michael, M. Jr. (1942). Staphylococcus aureus pneumonia: with special reference to its occurrence as a complication of influenza. J. Am. Med. Assoc. 118, 869-874. doi: 10.1001/jama.1942.02830110011004

Michaelis, M., Doerr, H. W., and Cinatl, J. Jr. (2009). Novel swine-origin influenza A virus in humans: another pandemic knocking at the door. Med. Microbiol. Immunol. 198, 175-183. doi: 10.1007/s00430-009-0118-5

Michaels, R. H., Myerowitz, R. L., and Klaw, R. (1977). Potentiation of experimental meningitis due to Haemophilus influenzae by influenza A virus. J. Infect. Dis. 135, 641-645. doi: 10.1093/infdis/135.4.641

Morens, D. M., Taubenberger, J. K., and Fauci, A. S. (2008). Predominant role of bacterial pneumonia as a cause of death in pandemic influenza: implications for pandemic influenza preparedness. J. Infect. Dis. 198, 962-970. doi: 10.1086/ 591708

Morse, S. S., Mazet, J. A., Woolhouse, M., Parrish, C. R., Carroll, D., Karesh, W. B., et al. (2012). Prediction and prevention of the next pandemic zoonosis. Lancet 380, 1956-1965. doi: 10.1016/S0140-6736(12)61684-5

Mulcahy, M. E., Leech, J. M., Renauld, J. C., Mills, K. H., and McLoughlin, R. M. (2016). Interleukin-22 regulates antimicrobial peptide expression and keratinocyte differentiation to control Staphylococcus aureus colonization of the nasal mucosa. Mucosal Immunol. 9, 1429-1441. doi: 10.1038/mi. 2016.24

Mulcahy, M. E., and McLoughlin, R. M. (2016). Staphylococcus aureus and Influenza A Virus: partners in coinfection. MBio 7:e2068-16. doi: 10.1128/mBio. 02068-16

Murphy, F. A. (1998). Emerging zoonoses. Emerg. Infect. Dis. 4, 429-435. doi: 10.3201/eid0403.980324

Murphy, T. F. (2003). Respiratory infections caused by non-typeable Haemophilus influenzae. Curr. Opin. Infect. Dis. 16, 129-134. doi: 10.1097/00001432200304000-00009

Murphy, T. F., Brauer, A. L., Grant, B. J., and Sethi, S. (2005). Moraxella catarrhalis in chronic obstructive pulmonary disease: burden of disease and immune response. Am. J. Respir. Crit. Care Med. 172, 195-199. doi: 10.1164/rccm. 200412-1747OC

Murray, R. J., Robinson, J. O., White, J. N., Hughes, F., Coombs, G. W., Pearson, J. C., et al. (2010). Community-acquired pneumonia due to pandemic A(H1N1)2009 influenzavirus and methicillin resistant Staphylococcus aureus co-infection. PLoS ONE 5:e8705. doi: 10.1371/journal.pone.0008705

Nakajima, K., Desselberger, U., and Palese, P. (1978). Recent human influenza A (H1N1) viruses are closely related genetically to strains isolated in 1950. Nature 274, 334-339. doi: 10.1038/274334a0

Nayak, D. P., Balogun, R. A., Yamada, H., Zhou, Z. H., and Barman, S. (2009). Influenza virus morphogenesis and budding. Virus Res. 143, 147-161. doi: 10.1016/j.virusres.2009.05.010

Newing, W. J., and Christie, R. (1947). Meningitis; isolation of an organism resembling Neisseria catarrhalis from cerebro-spinal fluid; report of a case. Med. J. Aust. 1, 306.

Nguyen, T., Kyle, U. G., Jaimon, N., Tcharmtchi, M. H., Coss-Bu, J. A., Lam, F., et al. (2012). Coinfection with Staphylococcus aureus increases risk of severe coagulopathy in critically ill children with influenza A (H1N1) virus infection. Crit. Care Med. 40, 3246-3250. doi: 10.1097/CCM.0b013e318260c7f8

Nichol, K. L., Wuorenma, J., and von Sternberg, T. (1998). Benefits of influenza vaccination for low-, intermediate-, and high-risk senior citizens. Arch. Intern. Med. 158, 1769-1776. doi: 10.1001/archinte.158.16.1769

Okamoto, S., Kawabata, S., Nakagawa, I., Okuno, Y., Goto, T., Sano, K., et al. (2003). Influenza A virus-infected hosts boost an invasive type of Streptococcus pyogenes infection in mice. J. Virol. 77, 4104-4112. doi: 10.1128/JVI.77.7.4104-4112.2003

Olson, D. R., Simonsen, L., Edelson, P. J., and Morse, S. S. (2005). Epidemiological evidence of an early wave of the 1918 influenza pandemic in New York City. Proc. Natl. Acad. Sci. U.S.A. 102, 11059-11063. doi: 10.1073/pnas.0408290102

Onofrio, J. M., Shulkin, A. N., Heidbrink, P. J., Toews, G. B., and Pierce, A. K. (1981). Pulmonary clearance and phagocytic cell response to normal pharyngeal flora. Am. Rev. Respir. Dis. 123, 222-225.

Opie, E. L., Blake, F., Small, J. C., and Rivers, T. M. (1921). “The pneumonias and other infections of the respiratory tract accompanying influenza and measles. St. Louis: CV Mosby," in Epidemic Respiratory Disease, eds E. L. Opie, F. G. Blake, J. C. Small, and T. M. Rivers (New York, NY: Forgotten Books), 107-281.

Osterhaus, A. D., Rimmelzwaan, G. F., Martina, B. E., Bestebroer, T. M., and Fouchier, R. A. (2000). Influenza B virus in seals. Science 288, 1051-1053. doi: $10.1126 /$ science.288.5468.1051

Oxford, J. S., Sefton, A., Jackson, R., Innes, W., Daniels, R. S., and Johnson, N. P. (2002). World war I may have allowed the emergence of "Spanish" influenza. Lancet Infect. Dis. 2, 111-114. doi: 10.1016/S1473-3099(02)00185-8

Pai, R., Gertz, R. E., Whitney, C. G., and Beall, B. (2005a). Clonal association between Streptococcus pneumoniae serotype 23A, circulating within the United States, and an internationally dispersed clone of serotype 23F. J. Clin. Microbiol. 43, 5440-5444.

Pai, R., Moore, M. R., Pilishvili, T., Gertz, R. E., Whitney, C. G., Beall, B., et al. (2005b). Postvaccine genetic structure of Streptococcus pneumoniae serotype 19A from children in the United States. J. Infect. Dis. 192, 1988-1995. 
Palacios, G., Hornig, M., Cisterna, D., Savji, N., Bussetti, A. V., Kapoor, V., et al. (2009). Streptococcus pneumoniae coinfection is correlated with the severity of H1N1 pandemic influenza. PLoS ONE 4:e8540. doi: 10.1371/journal.pone. 0008540

Park, I. H., Pritchard, D. G., Cartee, R., Brandao, A., Brandileone, M. C., and Nahm, M. H. (2007). Discovery of a new capsular serotype (6C) within serogroup 6 of Streptococcus pneumoniae. J. Clin. Microbiol. 45, 1225-1233. doi: 10.1128/JCM. 02199-06

Parrish, C. R., Murcia, P. R., and Holmes, E. C. (2015). Influenza virus reservoirs and intermediate hosts: dogs, horses, and new possibilities for influenza virus exposure of humans. J. Virol. 89, 2990-2994. doi: 10.1128/JVI.03146- 14

Payne, A. M. (1958). Some aspects of the epidemiology of the 1957 influenza pandemic. Proc. R. Soc. Med. 51, 1009-1015.

Peckham, R. (2016). Epidemics in Modern Asia. Cambridge: Cambridge University Press. doi: 10.1017/CBO9781316026939

Peiris, J. S., Poon, L. L., and Guan, Y. (2009). Emergence of a novel swine-origin influenza A virus (S-OIV) H1N1 virus in humans. J. Clin. Virol. 45, 169-173. doi: $10.1016 /$ j.jcv.2009.06.006

Peltola, V. T., and McCullers, J. A. (2004). Respiratory viruses predisposing to bacterial infections: role of neuraminidase. Pediatr. Infect. Dis. J. 23, S87-S97. doi: 10.1097/01.inf.0000108197.81270.35

Peltola, V. T., Murti, K. G., and McCullers, J. A. (2005). Influenza virus neuraminidase contributes to secondary bacterial pneumonia. J. Infect. Dis. 192, 249-257. doi: 10.1086/430954

Petersdorf, R. G., Fusco, J. J., Harter, D. H., and Albrink, W. S. (1959). Pulmonary infections complicating Asian influenza. AMA Arch. Intern. Med. 103, 262-272. doi: 10.1001/archinte.1959.00270020090010

Pittet, L. F., and Posfay-Barbe, K. M. (2012). Pneumococcal vaccines for children: a global public health priority. Clin. Microbiol. Infect. 18(Suppl. 5), 25-36. doi: 10.1111/j.1469-0691.2012.03938.x

Plotkowski, M. C., Puchelle, E., Beck, G., Jacquot, J., and Hannoun, C. (1986). Adherence of type I Streptococcus pneumoniae to tracheal epithelium of mice infected with influenza A/PR8 virus. Am. Rev. Respir. Dis. 134, 1040-1044. doi: 10.1164/arrd.1986.134.5.1040

Potter, C. W. (2001). A history of influenza. J. Appl. Microbiol. 91, 572-579. doi: 10.1046/j.1365-2672.2001.01492.x

Racaniello, V. (2009). The A, B, and C of Influenza Virus. Available at: http://www. virology.ws/2009/09/22/the-a-b-and-c-of-influenza-virus/

Randolph, A. G., Vaughn, F., Sullivan, R., Rubinson, L., Thompson, B. T., Yoon, G., et al. (2011). Critically ill children during the 2009-2010 influenza pandemic in the United States. Pediatrics 128:e1450-8. doi: 10.1542/peds. 2011-0774

Reid, A. H., Taubenberger, J. K., and Fanning, T. G. (2001). The 1918 Spanish influenza:integrating history and biology. Microbes Infect. 3, 81-87. doi: 10.1016/S1286-4579(00)01351-4

Rice, T. W., Rubinson, L., Uyeki, T. M., Vaughn, F. L., John, B. B., Miller, R. R., et al. (2012). Critical illness from 2009 pandemic influenza A virus and bacterial coinfection in the United States. Crit. Care Med. 40, 1487-1498. doi: 10.1097/ CCM.0b013e3182416f23

Rizzo, C., Caporali, M. G., and Rota, M. C. (2010). Pandemic influenza and pneumonia due to Legionella pneumophila: a frequently underestimated coinfection. Clin. Infect. Dis. 51:115. doi: 10.1086/653444

Robertson, L., Caley, J. P., and Moore, J. (1958). Importance of Staphylococcus aureus in pneumonia in the 1957 epidemic of influenza A. Lancet 2, 233-236. doi: 10.1016/S0140-6736(58)90060-6

Robinson, K. M., Choi, S. M., McHugh, K. J., Mandalapu, S., Enelow, R. I., Kolls, J. K., et al. (2013). Influenza A exacerbates Staphylococcus aureus pneumonia by attenuating IL-1beta production in mice. J. Immunol. 191, 5153-5159. doi: 10.4049/jimmunol.1301237

Robinson, K. M., Kolls, J. K., and Alcorn, J. F. (2015). The immunology of influenza virus-associated bacterial pneumonia. Curr. Opin. Immunol. 34, 59-67. doi: 10.1016/j.coi.2015.02.002

Robinson, K. M., McHugh, K. J., Mandalapu, S., Clay, M. E., Lee, B., Scheller, E. V., et al. (2014). Influenza A virus exacerbates Staphylococcus aureus pneumonia in mice by attenuating antimicrobial peptide production. J. Infect. Dis. 209, 865-875. doi: 10.1093/infdis/jit527

Rock, K. L., and Kono, H. (2008). The inflammatory response to cell death. Annu. Rev. Pathol. 3, 99-126. doi: 10.1146/annurev.pathmechdis.3.121806.151456
Rosenstein, N. E., and Perkins, B. A. (2000). Update on Haemophilus influenzae serotype b and meningococcal vaccines. Pediatr. Clin. North Am. 47, 337-352. doi: 10.1016/S0031-3955(05)70210-8

Rupp, S., Ambata, P., Narat, V., and Giles-Vernick, T. (2016). Beyond the cut hunter: a historical epidemiology of HIV beginnings in central africa. Ecohealth 13, 661-671. doi: 10.1007/s10393-016-1189-6

Samji, T. (2009). Influenza A: understanding the viral life cycle. Yale J. Biol. Med. $82,153-159$.

Sanford, B. A., and Ramsay, M. A. (1987). Bacterial adherence to the upper respiratory tract of ferrets infected with influenza A virus. Proc. Soc. Exp. Biol. Med. 185, 120-128. doi: 10.3181/00379727-185-42525

Sanford, B. A., Shelokov, A., and Ramsay, M. A. (1978). Bacterial adherence to virus-infected cells: a cell culture model of bacterial superinfection. J. Infect. Dis. 137, 176-181. doi: 10.1093/infdis/137.2.176

Schoenborn, J. R., and Wilson, C. B. (2007). Regulation of interferon-gamma during innate and adaptive immune responses. Adv. Immunol. 96, 41-101. doi: 10.1016/S0065-2776(07)96002-2

Schwarzmann, S. W., Adler, J. L., Sullivan, R. J. Jr., and Marine, W. M. (1971) Bacterial pneumonia during the Hong Kong influenza epidemic of 1968-1969. Arch. Intern. Med. 127, 1037-1041. doi: 10.1001/archinte.1971.00310180053006

Scott, M. J., Hoth, J. J., Stagner, M. K., Gardner, S. A., Peyton, J. C., and Cheadle, W. G. (2004). CD40-CD154 interactions between macrophages and natural killer cells during sepsis are critical for macrophage activation and are not interferon gamma dependent. Clin. Exp. Immunol. 137, 469-477. doi: 10.1111/ j.1365-2249.2004.02547.x

Seki, M., Yanagihara, K., Higashiyama, Y., Fukuda, Y., Kaneko, Y., Ohno, H., et al. (2004). Immunokinetics in severe pneumonia due to influenza virus and bacteria coinfection in mice. Eur. Respir. J. 24, 143-149. doi: 10.1183/09031936. 04.00126103

Selinger, D. S., Reed, W. P., and McLaren, L. C. (1981). Model for studying bacterial adherence to epithelial cells infected with viruses. Infect. Immun. 32, 941-944.

Shahangian, A., Chow, E. K., Tian, X., Kang, J. R., Ghaffari, A., Liu, S. Y., et al. (2009). Type I IFNs mediate development of postinfluenza bacterial pneumonia in mice. J. Clin. Invest. 119, 1910-1920. doi: 10.1172/JCI35412

Sharma-Chawla, N., Sender, V., Kershaw, O., Gruber, A. D., Volckmar, J., Henriques-Normark, B., et al. (2016). Influenza A virus infection predisposes hosts to secondary infection with different Streptococcus pneumoniae serotypes with similar outcome but serotype-specific manifestation. Infect. Immun. 84, 3445-3457. doi: 10.1128/IAI.00422-16

Shinya, K., Ebina, M., Yamada, S., Ono, M., Kasai, N., and Kawaoka, Y. (2006). Avian flu: influenza virus receptors in the human airway. Nature 440, 435-436. doi: $10.1038 / 440435$ a

Shope, R. E. (1931). Swine Influenza: Iii. Filtration experiments and etiology. J. Exp. Med. 54, 373-385. doi: 10.1084/jem.54.3.373

Shrestha, S., Foxman, B., Weinberger, D. M., Steiner, C., Viboud, C., and Rohani, P. (2013). Identifying the interaction between influenza and pneumococcal pneumonia using incidence data. Sci. Transl. Med. 5:191ra184. doi: 10.1126/ scitranslmed.3005982

Siegel, S. J., Roche, A. M., and Weiser, J. N. (2014). Influenza promotes pneumococcal growth during coinfection by providing host sialylated substrates as a nutrient source. Cell Host Microbe 16, 55-67. doi: 10.1016/j. chom.2014.06.005

Smith, A. M., and McCullers, J. A. (2014). Secondary bacterial infections in influenza virus infection pathogenesis. Curr. Top. Microbiol. Immunol. 385, 327-356. doi: 10.1007/82_2014_394

Smith, F. B. (1995). The Russian influenza in the United Kingdom, 1889-1894. Soc. Hist. Med. 8, 55-73. doi: 10.1093/shm/8.1.55

Spooner, L. H., Scott, J. M., and Heath, E. H. (1919). A bacteriologic study of the influenza epidemic at Camp Devens. JAMA 72, 155-159. doi: 10.1001/jama. 1919.02610030001001

Steinhauer, D. A. (1999). Role of hemagglutinin cleavage for the pathogenicity of influenza virus. Virology 258, 1-20. doi: 10.1006/viro.1999.9716

Sullivan, K. M., Monto, A. S., and Longini, I. M. Jr. (1993). Estimates of the US health impact of influenza. Am. J. Public Health 83, 1712-1716. doi: 10.2105/ AJPH.83.12.1712

Sun, K., and Metzger, D. W. (2008). Inhibition of pulmonary antibacterial defense by interferon-gamma during recovery from influenza infection. Nat. Med. 14, 558-564. doi: $10.1038 / \mathrm{nm} 1765$ 
Takase, H., Nitanai, H., Yamamura, E., and Otani, T. (1999). Facilitated expansion of pneumococcal colonization from the nose to the lower respiratory tract in mice preinfected with influenza virus. Microbiol. Immunol. 43, 905-907. doi: 10.1111/j.1348-0421.1999.tb01226.x

Tashiro, M., Ciborowski, P., Reinacher, M., Pulverer, G., Klenk, H. D., and Rott, R. (1987). Synergistic role of staphylococcal proteases in the induction of influenza virus pathogenicity. Virology 157, 421-430. doi: 10.1016/0042-6822(87) 90284-4

Taubenberger, J. K., and Morens, D. M. (2008). The pathology of influenza virus infections. Annu. Rev. Pathol. 3, 499-522. doi: 10.1146/annurev.pathmechdis.3. 121806.154316

Taubenberger, J. K., Reid, A. H., Janczewski, T. A., and Fanning, T. G. (2001). Integrating historical, clinical and molecular genetic data in order to explain the origin and virulence of the 1918 Spanish influenza virus. Philos. Trans. $R$. Soc. Lond. B Biol. Sci. 356, 1829-1839. doi: 10.1098/rstb.2001.1020

Tillett, H. E., Smith, J. W., and Gooch, C. D. (1983). Excess deaths attributable to influenza in England and Wales: age at death and certified cause. Int. J. Epidemiol. 12, 344-352. doi: 10.1093/ije/12.3.344

Tong, S., Li, Y., Rivailler, P., Conrardy, C., Castillo, D. A., Chen, L. M., et al. (2012). A distinct lineage of influenza A virus from bats. Proc. Natl. Acad. Sci. U.S.A. 109, 4269-4274. doi: 10.1073/pnas.1116200109

Tong, S. Y., Davis, J. S., Eichenberger, E., Holland, T. L., Fowler, V. G. Jr., et al. (2015). Staphylococcus aureus infections: epidemiology, pathophysiology, clinical manifestations, and management. Clin. Microbiol. Rev. 28, 603-661. doi: 10.1128/CMR.00134-14

Topham, N. J., and Hewitt, E. W. (2009). Natural killer cell cytotoxicity: how do they pull the trigger? Immunology 128, 7-15. doi: 10.1111/j.1365-2567.2009. 03123.x

Trilla, A., Trilla, G., and Daer, C. (2008). The 1918 "Spanish Flu” in Spain. Clin. Infect. Dis. 47, 668-673. doi: 10.1086/590567

Valleron, A. J., Cori, A., Valtat, S., Meurisse, S., Carrat, F., and Boelle, P. Y. (2010). Transmissibility and geographic spread of the 1889 influenza pandemic. Proc. Natl. Acad. Sci. U.S.A. 107, 8778-8781. doi: 10.1073/pnas.1000886107

van der Sluijs, K. F., van der Poll, T., Lutter, R., Juffermans, N. P., and Schultz, M. J. (2010). Bench-to-bedside review: bacterial pneumonia with influenza - pathogenesis and clinical implications. Crit. Care 14:219. doi: 10.1186/cc 8893

Verduin, C. M., Hol, C., Fleer, A., van Dijk, H., and van Belkum, A. (2002). Moraxella catarrhalis: from emerging to established pathogen. Clin. Microbiol. Rev. 15, 125-144. doi: 10.1128/CMR.15.1.125-144.2002

Wadowsky, R. M., Mietzner, S. M., Skoner, D. P., Doyle, W. J., and Fireman, P. (1995). Effect of experimental influenza A virus infection on isolation of Streptococcus pneumoniae and other aerobic bacteria from the oropharynges of allergic and nonallergic adult subjects. Infect. Immun. 63, 1153-1157.

Wang, T. T., and Palese, P. (2009). Unraveling the mystery of swine influenza virus. Cell 137, 983-985. doi: 10.1016/j.cell.2009.05.032

Webster, R. G., Bean, W. J., Gorman, O. T., Chambers, T. M., and Kawaoka, Y. (1992). Evolution and ecology of influenza A viruses. Microbiol. Rev. 56, 152-179.

Weinberger, D. M., Simonsen, L., Jordan, R., Steiner, C., Miller, M., and Viboud, C. (2012). Impact of the 2009 influenza pandemic on pneumococcal pneumonia hospitalizations in the United States. J. Infect. Dis. 205, 458-465. doi: 10.1093/ infdis/jir749

Wenger, J. D. (1998). Epidemiology of Haemophilus influenzae type b disease and impact of Haemophilus influenzae type b conjugate vaccines in the United States and Canada. Pediatr. Infect. Dis. J. 17(9 Suppl.), S132-S136.

Wertheim, H. F., Melles, D. C., Vos, M. C., van Leeuwen, W., van Belkum, A., Verbrugh, H. A., et al. (2005). The role of nasal carriage in Staphylococcus aureus infections. Lancet Infect. Dis. 5, 751-762. doi: 10.1016/S1473-3099(05)70295-4
World Health Organization (2016). Influenza (Seasonal) Factsheet. Available at: http://www.who.int/mediacentre/factsheets/fs211/en/

World Health Organization (2017). Smallpox. Available at: http://web.archive. org/web/20070921235036/http://www.who.int/mediacentre/factsheets/ smallpox/en/

Wu, S. W., de Lencastre, H., and Tomasz, A. (2005). Expression of high-level methicillin resistance in Staphylococcus aureus from the Staphylococcus sciuri mec A homologue: role of mutation(s) in the genetic background and in the coding region of mec A. Microb. Drug Resist. 11, 215-224. doi: 10.1089/mdr. 2005.11.215

Wu, Y., Mao, H., Ling, M. T., Chow, K. H., Ho, P. L., Tu, W., et al. (2011). Successive influenza virus infection and Streptococcus pneumoniae stimulation alter human dendritic cell function. BMC Infect. Dis. 11:201. doi: 10.1186/14712334-11-201

Wu, Y., Wu, Y., Tefsen, B., Shi, Y., and Gao, G. F. (2014). Bat-derived influenzalike viruses H17N10 and H18N11. Trends Microbiol. 22, 183-191. doi: 10.1016/ j.tim.2014.01.010

Wyde, P. R., Six, H. R., Ambrose, M. W., and Throop, B. J. (1989). Influenza virus infection and bacterial clearance in young adult and aged mice. J. Gerontol. 44, B118-B124. doi: 10.1093/geronj/44.5.b118

Yamashita, M., Krystal, M., Fitch, W. M., and Palese, P. (1988). Influenza B virus evolution: co-circulating lineages and comparison of evolutionary pattern with those of influenza A and C viruses. Virology 163, 112-122. doi: 10.1016/00426822(88)90238-3

Yang, M., Gao, H., Chen, J., Xu, X., Tang, L., Yang, Y., et al. (2016a). Bacterial coinfection is associated with severity of avian influenza A (H7N9), and procalcitonin is a useful marker for early diagnosis. Diagn. Microbiol. Infect. Dis. 84, 165-169. doi: 10.1016/j.diagmicrobio.2015.10.018

Yang, R., Cui, Y., and Bi, Y. (2016b). Perspectives on Yersinia pestis: a model for studying zoonotic pathogens. Adv. Exp. Med. Biol. 918, 377-391.

Youzbashi, E., Marschall, M., Chaloupka, I., and Meier-Ewert, H. (1996). [Distribution of influenza $\mathrm{C}$ virus infection in dogs and pigs in Bavaria]. Tierarztl. Prax. 24, 337-342.

Zambon, M. C. (2001). The pathogenesis of influenza in humans. Rev. Med. Virol. 11, 227-241. doi: 10.1002/rmv.319

Zumla, A., Hui, D. S., Al-Tawfiq, J. A., Gautret, P., McCloskey, B., and Memish, Z. A. (2014). Emerging respiratory tract infections. Lancet Infect. Dis. 14, 910-911. doi: 10.1016/S1473-3099(14)70899-0

Conflict of Interest Statement: SC acts as principal investigator for clinical trials and other studies sponsored by the University Hospital Southampton NHS Foundation Trust/University of Southampton that are funded by vaccine manufacturers but receives no personal payments from them. SC has also participated in advisory boards for vaccine manufacturers but receives no personal payments for this work. SC has received financial assistance from vaccine manufacturers to attend conferences. All grants and honoraria are paid into accounts within the University of Southampton, or to independent charities. DC was employed for 18 months on a GSK funded research project in 2014/15.

The other author declares that the research was conducted in the absence of any commercial or financial relationships that could be construed as a potential conflict of interest.

Copyright (c) 2017 Morris, Cleary and Clarke. This is an open-access article distributed under the terms of the Creative Commons Attribution License (CC BY). The use, distribution or reproduction in other forums is permitted, provided the original author(s) or licensor are credited and that the original publication in this journal is cited, in accordance with accepted academic practice. No use, distribution or reproduction is permitted which does not comply with these terms. 